\title{
Fracturing of the Soft Rock Surrounding a Roadway Subjected to Mining at Kouzidong Coal Mine
}

\author{
Zhili Su, ${ }^{1,2}$ Wenbing Xie $\mathbb{C D}^{1},{ }^{1}$ Shengguo Jing, ${ }^{2}$ Xingkai Wang, ${ }^{2}$ and Qingteng Tang ${ }^{2}$ \\ ${ }^{1}$ State Key Laboratory of Coal Resources and Safe Mining, China University of Mining and Technology, Xuzhou 221116, China \\ ${ }^{2}$ School of Mines, China University of Mining and Technology, Xuzhou 221116, China \\ Correspondence should be addressed to Wenbing Xie; tb17020012b0@cumt.edu.cn
}

Received 10 September 2019; Revised 27 March 2020; Accepted 6 May 2020; Published 25 August 2020

Academic Editor: Yuqing Zhang

Copyright (C) 2020 Zhili Su et al. This is an open access article distributed under the Creative Commons Attribution License, which permits unrestricted use, distribution, and reproduction in any medium, provided the original work is properly cited.

\begin{abstract}
The fracture development and distribution around the deep soft rock roadway are pivotal to any underground design. In this paper, both field investigation and numerical simulation were taken to study the fracture evolution and rock deformation of a coal mine roadway at Kouzidong mine, Fuyang, Anhui Province, China. Based on the borehole imaging technique, we found an asymmetric distribution of the fracture zone in the surrounding rock of the roadway. By analyzing the $C$ value of the fractures in the borehole images, we found that the fracture interval distribution of the surrounding rock of the tunnel, the number of fractures will fluctuate decrease with the increase of the depth. To effectively study the fracture propagation and distribution of the roadway under longwall retreatment and roadway excavation, the global-local numerical technique was applied via FLAC3D and PFC2D. In the roadway excavation process, fractures were first formed in the shallow section of the roadway and progressively propagated toward the deeper soft rock layer; the main failure mechanism was a tensile failure. During longwall retreatment, fractures continuously developed toward the deeper soft rock layer. However, the failure mechanism transformed to shear failure. From numerical results, it can be seen that the stress concentration at the ribs was released, which led to shear failure at the roof and floor. Due to the extensive tensile cracks in the shallow section, the surrounding rock experienced expansion and fracture. The deep shear failure also induced the formation of the nonadjacent crushing zone and elastic zone, which is in line with the borehole imaging results.
\end{abstract}

\section{Introduction}

Due to the extensive exploitation of coal, available resources at shallow depth quickly diminish and mining activities below 1000 meters have gradually gained popularity [1]. The mechanical behavior of the rock mass is closely related to the mining method as the mining-induced stress redistribution can significantly influence the surrounding rock mass [2]. Compared with mining at shallow depth, the failure mechanism and mechanical properties of the surrounding rock around roadway are different at deep mining locations, where the large deformation and rheological phenomenon frequently occur [3]. The deformation of the surrounding rock is mainly due to the stress-induced fracture and expansion. To enhance the knowledge on the fracture distribution around the roadway and optimize the supporting design, it is pivotal to understand the crack development and distribution of the surrounding rock around the roadway.

To effectively study the fracture propagation around the soft rock roadway, a series of methods have been suggested, including field surveys [4], physical similarity modeling [5], and numerical simulations [6,7]. Ma et al. [8] used borehole imaging, geological radar, roof separation monitoring, and other means to study the fracture development process of the roadway roof. They found that the crack opening and the separation characteristic of this type of roadway are a dynamic process gradually developing upwards. Gao and Stead [9] used the discrete element model (DEM) to analyze the relationship between the major principal stress orientation and fracture distribution. They found that a roadway driven at a large angle $\left(75^{\circ}-90^{\circ}\right)$ with respect to the maximum horizontal stress suffers significantly more fracturing than 
that driven at a small angle $\left(0-15^{\circ}\right)$. With the development of numerical simulation theory, the technique of coupling simulation between the discrete element model (DEM) and the finite element model (FEM) has been used. This coupling calculation technique not only is more representative of the mechanical properties of nonlinear rock materials but also considerably reduces the model computation time. However, the combination of the two models is achieved by the displacement boundary conditions [10], where macroproperties of the material in both DEM and FEM have to be similar. When simulating multiple rock layers, the numerical results are not well aligned with field observations. To overcome the shortcomings of the coupling calculation, this paper implements the global-local simulation model. The global-local model was originally used for the prediction of the stresses in hard rock mine $[11,12]$, and it has been widely used in solving rock mechanics problems.

This paper investigated the fracture development and deformation of the surrounding rock around the roadway at the Kouzidong coal mine, where fractures were observed and monitored using borehole imaging at different locations. Based on the collected field data, a numerical simulation via PFC was also carried out to further investigate the failure mode and rock deformation around the roadway. The findings of this study will help engineers to better understand the fracture distribution around the roadway and, therefore, implement the appropriate supporting system.

The introduction should be succinct, with no subheadings. Limited figures may be included only if they are truly introductory and contain no new results.

\section{Field Conditions at Kouzidong Coal Mine}

2.1. Geological Conditions and Supporting Scheme. Kouzidong coal mine is located at Yingdong District, Fuyang City, Anhui Province, as displayed in Figure 1. The longwall panel for this study (121304 longwall face) locates at the west of the mining area, and it the third fully mechanized longwall face of the 13-1 coal seam. The longwall face is divided into two parts based on the gas drainage roadway, and the south and north sections; each section has a length of $247.4 \mathrm{~m}$ and $350 \mathrm{~m}$, respectively. The total length of the longwall panel is $1195.3 \mathrm{~m}$, with an inclined depth of cover from $704 \mathrm{~m}$ to $885 \mathrm{~m}$. The layout of the panel is illustrated in Figure 2. The roof of the longwall panel consists of mudstone, whereas the floor is composed of sandstone; see Figure 3. The two sides of the roadway are pillar and coal to be recovered. The roadway belongs to the deep buried solid coal roadway with thick seam. The roadway design is a semicircular arch with a $6.2 \mathrm{~m}$ width and $4.5 \mathrm{~m}$ height. The illustration is displayed in Figure 4 together with the supporting scheme.

2.2. Monitoring Stations. To study the fracture development and distribution around the roadway under mining activities and dynamic loading, two stations were installed at the roadway for monitoring purposes; see Figure 2. The two monitoring stations are $70 \mathrm{~m}$ and $150 \mathrm{~m}$ away from the

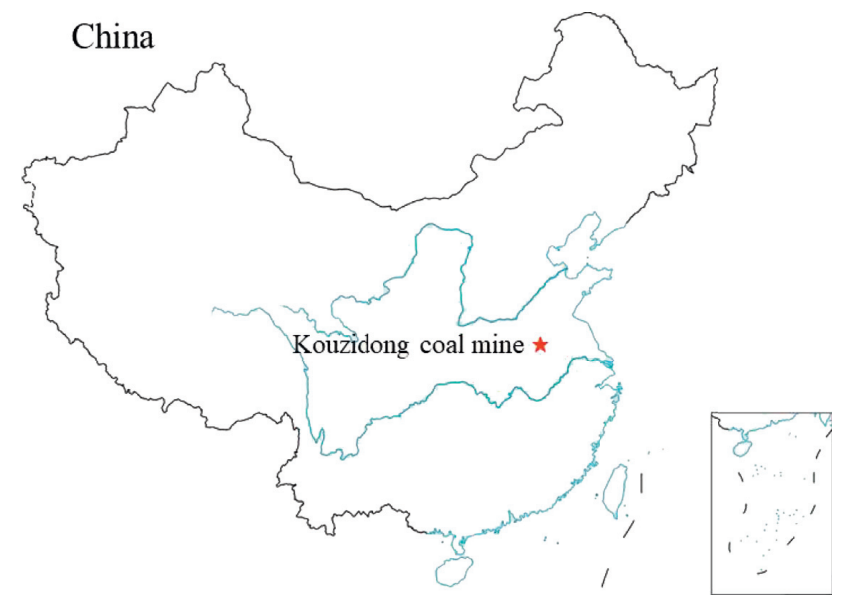

FIgURE 1: Location of Kouzidong coal mine.

longwall space at the time of installation, respectively. Every station contains 7 monitoring boreholes while station \#2 also has 7 displacement meters; the layout can be observed in Figure 5. Boreholes drilling into the roof have a length of $10 \mathrm{~m}$, whereas the boreholes at the ribs are $6 \mathrm{~m}$ long. Based on the observation from the monitoring stations, the roadway experienced significant deformation due to longwall retreatment. As a result, the semicircular arch was pressured into a rectangular shape, which can be seen in Figure 5 as well.

\subsubsection{Panoramic Digital Intelligent Borehole Imaging} Observation. The panoramic digital intelligent borehole imaging system can transform a panoramic image into a planar image through optical technology. Based on the technology, the panoramic image can either be processed into $2 \mathrm{D}$ or $3 \mathrm{D}$ images. The system can provide a $360^{\circ}$ unfolding image of the borehole wall and can form a $3 \mathrm{D}$ columnar borehole image.

In this field test, the ZKXG30 mine safe drilling trajectory detection device was used for monitoring, shown in Figure 6. The device mainly consists of a color camera probe, a video transmission line, a guide bar, a depth counter, and the main unit. The front-view CCD camera has a diameter of $22 \mathrm{~mm}$, which can be used to observe the boreholes with diameters greater than $28 \mathrm{~mm}$ and lengths less than $30 \mathrm{~m}$. The camera can detect the cracks that are larger than $0.1 \mathrm{~mm}$, and it is equipped with a high-precision electronic compass with an angular resolution of $0.1^{\circ}$. During monitoring, the monitoring depth and image can be automatically combined by hand-held microreceiver, and the planar review of the borehole wall image can be synthesized in real time.

According to the borehole imaging results, the fracture distribution, location, inclination angle, and opening width can be estimated. Through the observation of multiple boreholes, the coalescence of the fractures and the fracture distribution in larger zones can be analyzed to determine the extent of the loose zone around the roadway and the fracture level of the surrounding rock at different depths. 


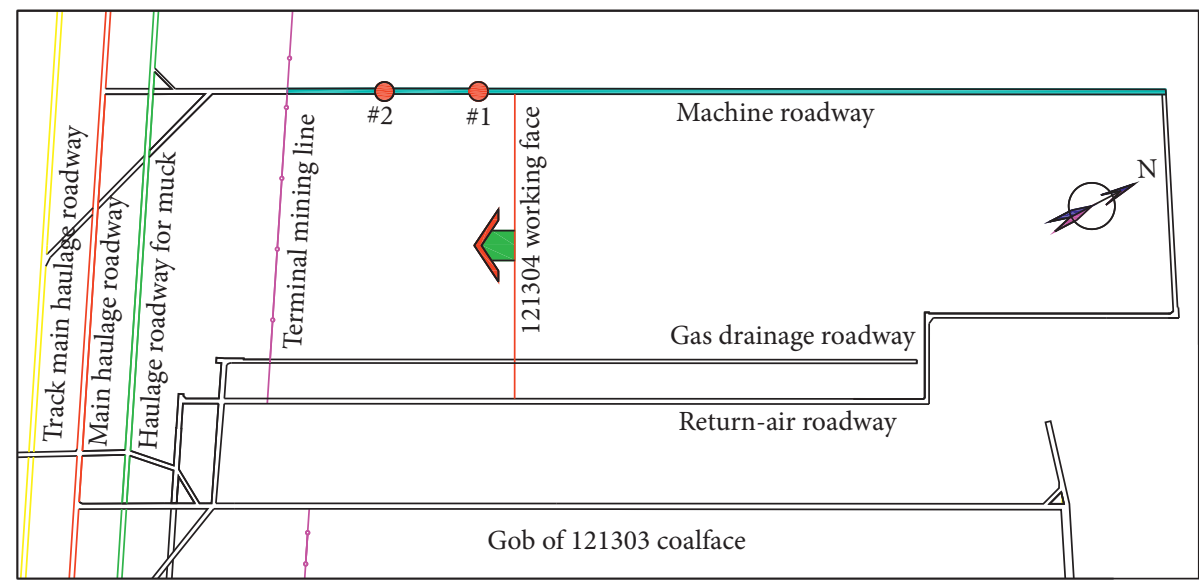

Displacement monitoring station

FIGURE 2: 121304 longwall face schematic view.

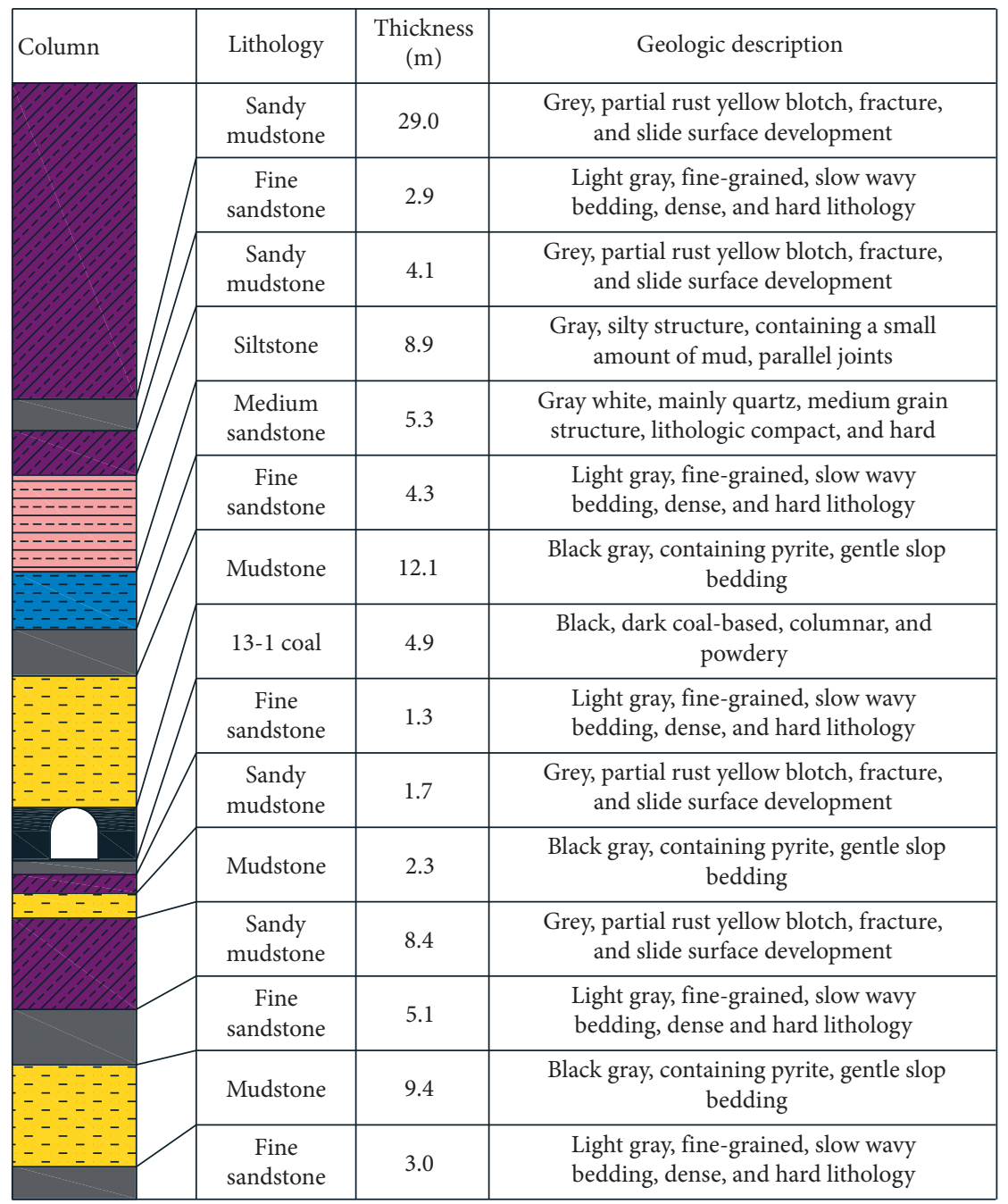

FIgURE 3: Geological structure at the mine site.

2.2.2. Movement of the Surrounding Rock. The displacement meter was used to monitor the movement of the surrounding rock around the roadway, which can reflect the degree of crack opening and closing at different locations from the roadway surface. KDW-1 type displacement meters were installed at the ribs while KDW-2 type displacement meters were mounted at 


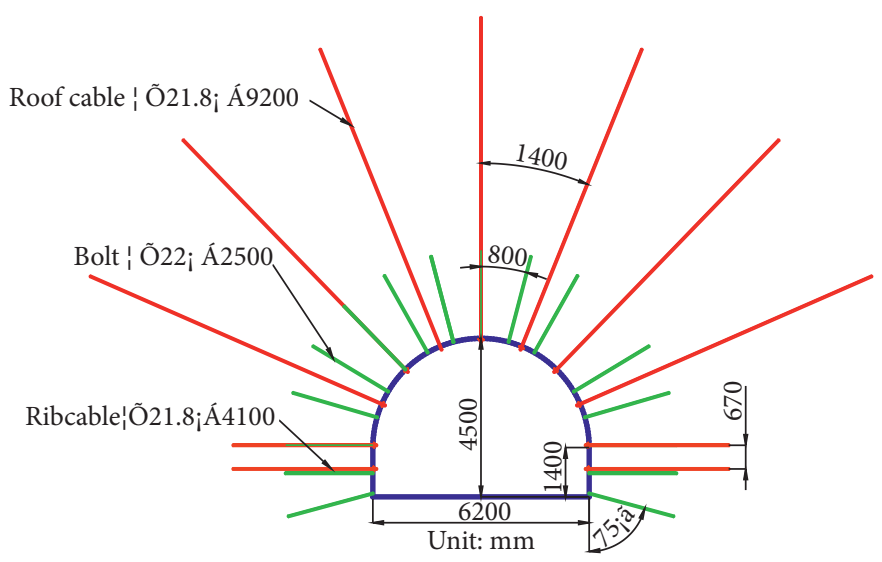

FIgURE 4: The primary support scheme.

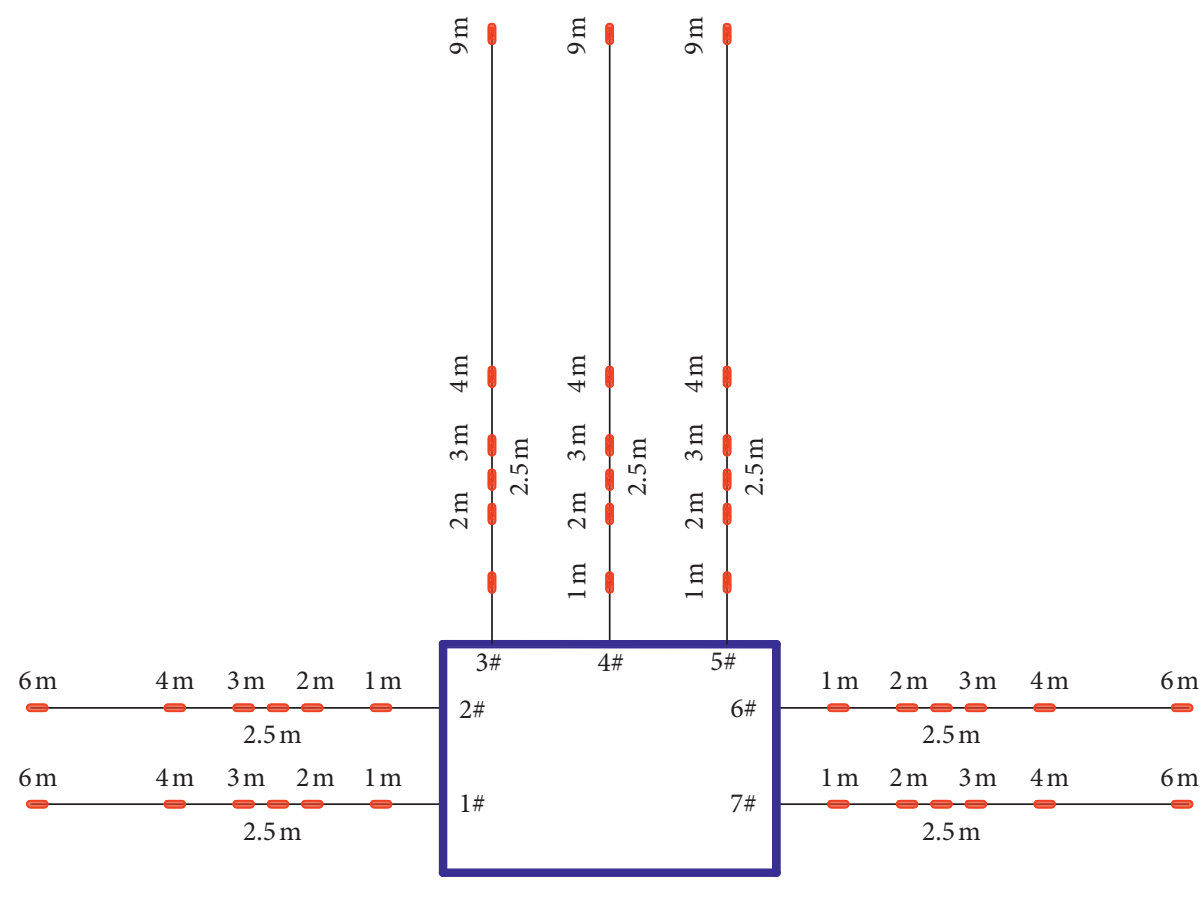

- Base point of multipoint displacement meter

FIgURE 5: Borehole imaging tool locations and displacement meter locations.

the roof; see Figures 7 and 8, respectively. According to the support design of the roadway, the installation points are determined to be $1 \mathrm{~m}, 2 \mathrm{~m}, 2.5 \mathrm{~m}, 3 \mathrm{~m}$, and $6 \mathrm{~m}$ from the ribs, and the installation points are $1 \mathrm{~m}, 2 \mathrm{~m}, 2.5 \mathrm{~m}, 4 \mathrm{~m}$, and $9 \mathrm{~m}$ away from the roof. \#1 and \#2 displacement meters were mounted in the surrounding rock of the pillar side of the roadway; \#6 and \#7 displacement meters were positioned at the mining side of the roadway, \#3-\#5 were placed at the roof of the roadway, as shown in Figure 5 again.

\section{Field Data Analysis}

3.1. Deformation of the Surrounding Rock. \#2 displacement meter aims to monitor the deformation of the surrounding rock at different depths of the 121304 longwall face during the mining process. The deformation of the surrounding rock of the roadway can be represented by the displacement meter measurements. The deformation of the rock mass between two adjacent installation points can be expressed by the difference in displacement between the two installation points.

Figure 9 depicts an overview of the roadway section. The $x$-axis represents the width of the roadway section, the $y$-axis represents the height of the roadway section, the $z$-axis represents the deformation of the rock mass between adjacent installation points of displacement meters, and the color label indicates the compressive or tensile deformation of the rock mass. As the color changes from purple to dark red, the deformation of rock mass also increases accordingly. The positions of cylinders in the figure indicate locations of installation points in the surrounding rock, and the height of 


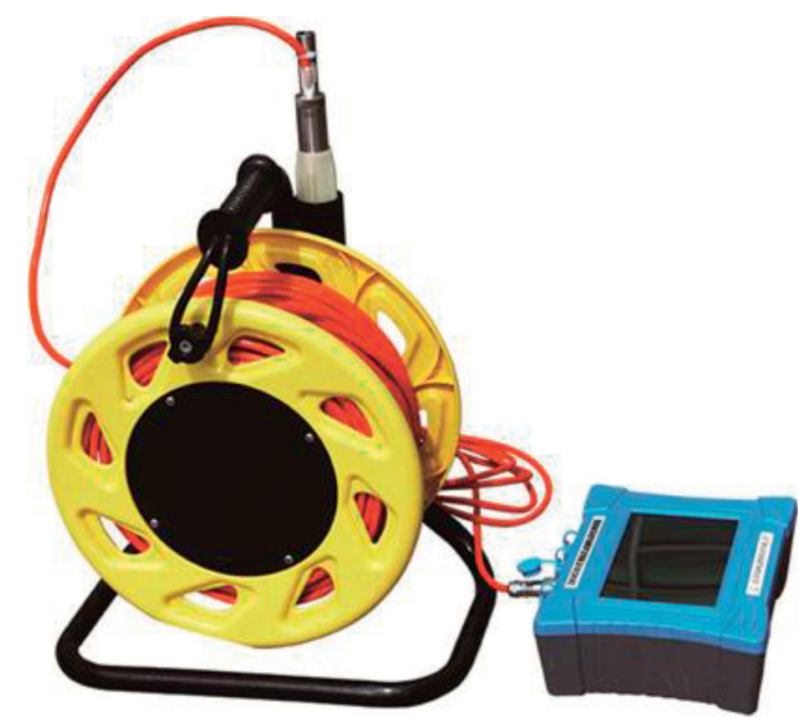

FIGURE 6: ZKXG30 mine safe drilling trajectory detection device.

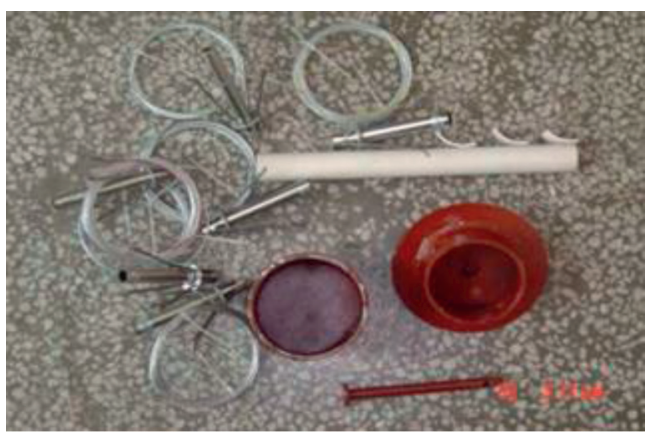

(a)

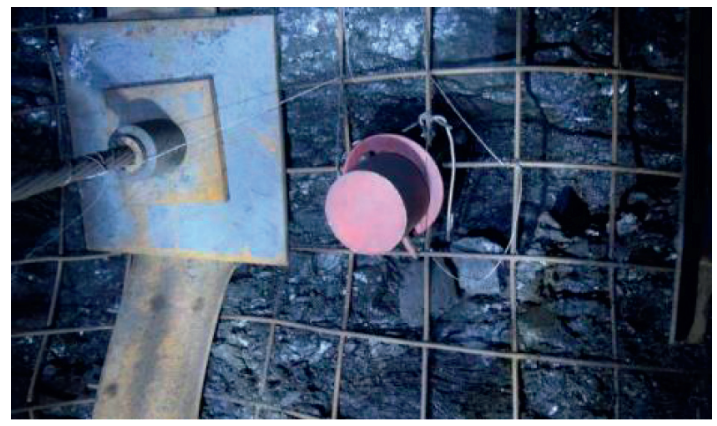

(b)

FIGURE 7: KDW-1 displacement meter at the rib: (a) displacement meter; (b) installation at the rib.

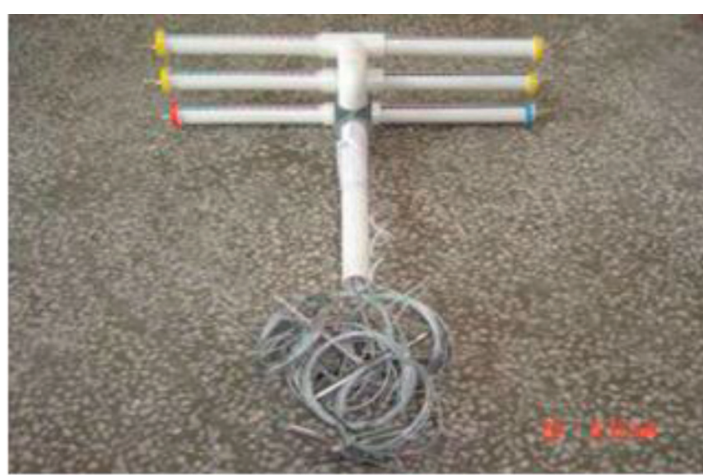

(a)

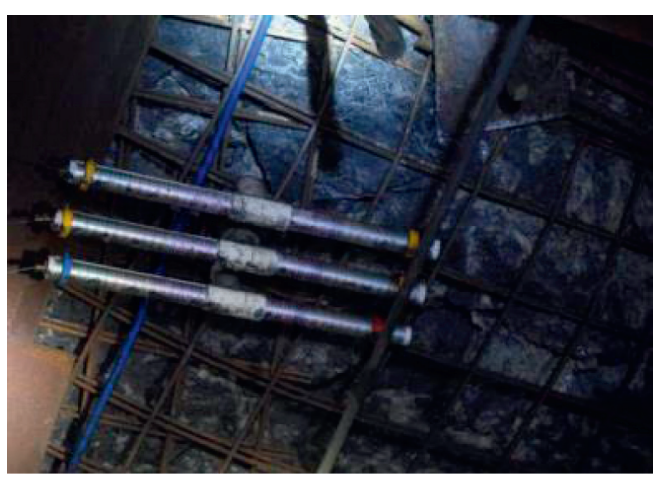

(b)

Figure 8: KDW-2 displacement meter at the roof: (a) displacement meter; (b) installation at the roof.

the cylinder denotes the amount of deformation of the rock mass, while the color of the cylinder corresponds to different deformation intervals as shown in the color label. According to this diagram, it is possible to analyze the deformation of the surrounding rock at different depths from the surface of the roadway under the influence of the dynamic loading caused by longwall mining.

Figure 9 also shows the relative displacement of the surrounding rock at different depths from the surface of the roadway when station $\# 2$ is $130 \mathrm{~m}, 90 \mathrm{~m}, 50 \mathrm{~m}$, and $10 \mathrm{~m}$ 


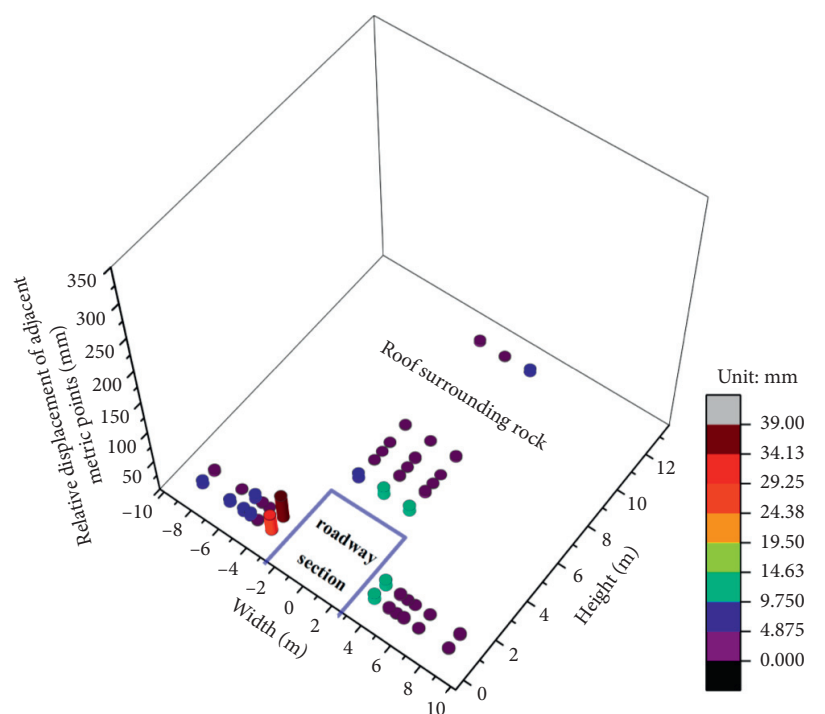

(a)

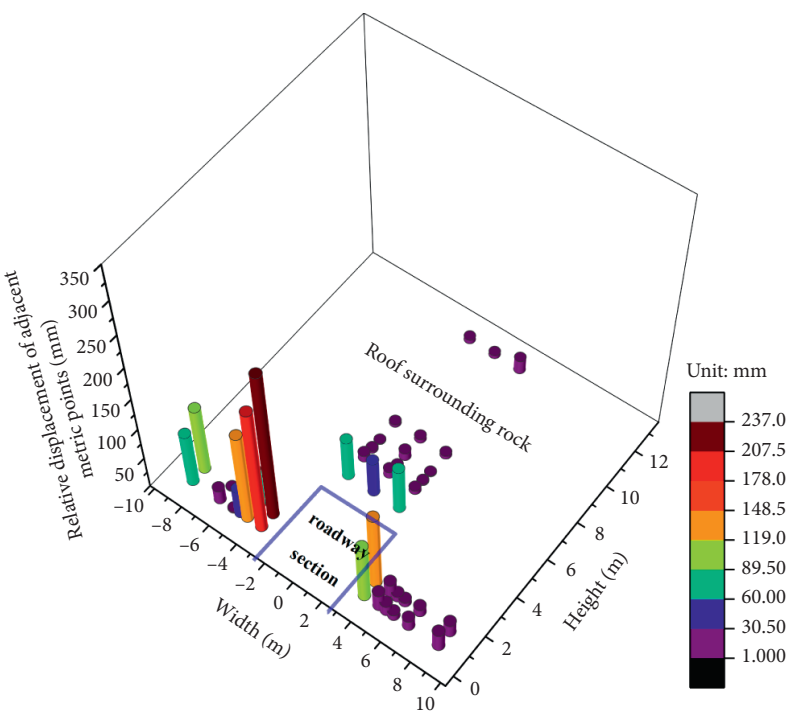

(c)

FIgURE 9: Monitoring results from displacement meters at station \#2: (a) $130 \mathrm{~m}$ from the longwall face; (b) $90 \mathrm{~m}$ from the longwall face; (c) $50 \mathrm{~m}$ from the longwall face; (d) $10 \mathrm{~m}$ from the longwall face.

away from the longwall face. From the figure, the following can be seen. (1) With the retreatment of the longwall face, there were extensive cracks quickly formed within $1 \mathrm{~m}$ from the roadway surface; the maximum deformation recorded was $334 \mathrm{~mm}$. Thereby, the deformation was also observed between 4 and $6 \mathrm{~m}$ distance from the ribs, with a maximum deformation of $209 \mathrm{~mm}$. (2) The deformation of the surrounding rock in the $2 \sim 4 \mathrm{~m}$ range of the roadway was less than other intervals, and the surrounding rock deformation in between was mainly elastic deformation. It shows that the surrounding rock of the roadway can be divided into three zones from the surface, i.e., crushing zone-elastic zonecrushing zone. (3) Although the surrounding rock in the range of $4 \sim 9 \mathrm{~m}$ of the roadway roof has a larger deformation than the surrounding rock in the range of $3 \sim 4 \mathrm{~m}$, it is still

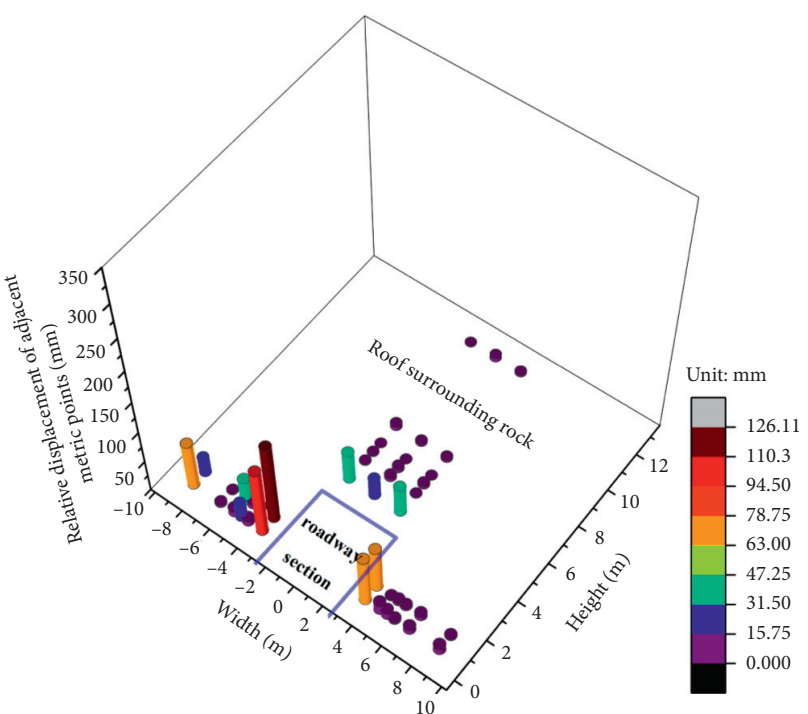

(b)

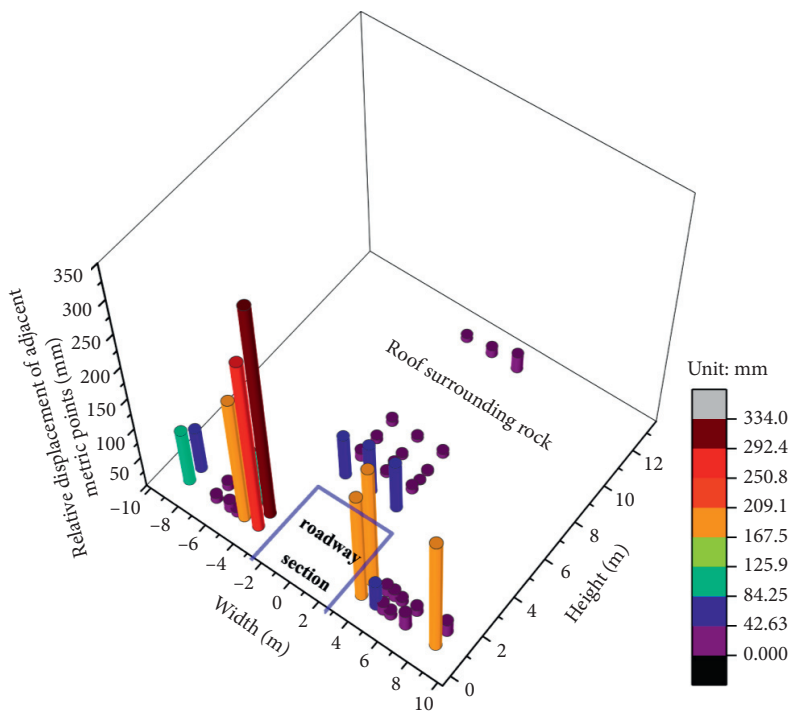

(d) under elastic condition. (4) The deformation at the ribs is considerably higher than that of the roof, indicating that the deformation compatibility between the ribs and the roof and floor of the roadway gradually deteriorates.

From Figure 9, it can also be observed that the deformation in the ranges of $0 \sim 1 \mathrm{~m}$ and $4 \sim 6 \mathrm{~m}$ is higher, suggesting that the fracture degree of the surrounding rock fracture is significantly larger than that of the adjacent zones near the surface of the roadway and within the supporting zone. According to the bolt bearing arch theory [13], the composite material is formed by the rock bolts and the surrounding rock, such that the integrity and supporting of rock in the range of the arch are better. On the other hand, rock bolts are not anchored near the surface of the roadway while the surrounding rock is also subjected to the tensile 
stress caused by the compression from the bolt ends. This tensile stress also aggravated the deformation and damage of the surrounding rock in this area.

\subsection{Fracture Development and Distribution of the Sur-} rounding Rock. After the excavation of roadway at deep cover depth, surrounding fractures will be formed due to stress redistribution, roadway advancement, temperature, and humidity change. The extent and degree of damage, as well as fracture evolution of the surrounding area, can be evaluated to determine the stability and support design of rock mass [14]. When station 2\# was $150 \mathrm{~m}$ away from the longwall surface, we have got the borehole images which are not influenced by longwall mining. By comparing the crack distribution at station \#2 and station \#1, the research purpose can be effectively studied.

\subsubsection{Analysis of Fracture Distribution in the Surrounding} Rock. Based on two monitoring stations, a total number of 14 boreholes were collected with a total imaging length of $108 \mathrm{~m}$. According to the observation, there are five kinds of cracks in the surrounding rock of the roadway, including crushing area, circumferential crack, longitudinal crack, oblique crack, and various cracks, as shown in Figure 10.

Figures 11 and 12 show borehole images collected from $\# 1$ and \#2 stations, respectively. The images were used to monitor the influence of longwall retreatment (station\#2) and roadway excavation (station \#1) on fracture distribution and development. Figure 11 (1) is the $2 \mathrm{D}$ view of the borehole from 0 to $360^{\circ}$, whereas the zoomed-in views of selected sections (red squares) can be observed in Figure 11 (2) to study the detail of cracks. Due to the integrity of other sections, they were not analyzed in detail. The length in Figure 11 (1) represents the distance from the surface of the roof to the imaging location. For example, $2 \mathrm{~m}$ means that the distance from the roof of the roadway to the image is $2 \mathrm{~m}$. The distribution and development of the cracks in the surrounding rock of the roadway can be seen from the borehole image.

Figure 11 is the distribution and development of cracks in the surrounding rock of the roadway arch under the influence of excavation. In the depth of $0-2 \mathrm{~m}$ from the roadway arch, cracks fully developed into two crushing zones, and the widths of the crushing zones are $0.5 \mathrm{~m}$ and $0.8 \mathrm{~m}$, respectively. Thereby, there are also cracks that can be seen between 6 and $8 \mathrm{~m}$, whereas one fracture is parallel to the borehole axis. Based on the results, it is clear that cracks only developed at shallow and deep locations from the roadway, and cracks are more intensive at the shallow location. Other sections of the rock mass remained relatively competent and there were not any noticeable cracks observed.

Figure 12 is the distribution and development of cracks in the surrounding rock of the roadway arch under the influence of longwall retreatment. Compared with the borehole results from station \#2, the zone of cracks is larger in the shallow part of the surrounding rock. There were five groups of crushing zones observed in the borehole, while the abscission layer was also found at the depth of $8.8 \mathrm{~m}$ (the white material was used for camera protection). According to the enlarged view of the section, it can be seen that denser fractures were formed in the surrounding rock. The comparison shows that the longwall retreatment facilitated the development of cracks inside the surrounding rock of the roadway arch.

\subsubsection{Analysis of Fracture Distribution in the Surrounding} Rock. The value of the circularity $(C)$ reflects the complexity of the boundary of the measured object. Hence, it was used in this study to determine the boundary complexity of the fractures in the surrounding rock. Based on the $C$-index of the surrounding rock at various borehole depths, the thickness of the loose zone can be effectively identified [15]. The $C$ value can be estimated using the following equation:

$$
C=\frac{P^{2}}{4 \pi A},
$$

where $P$ is the perimeter of the surrounding rock crack, and $A$ is the area of the surrounding rock crack [16].

For example, Figure 13 shows some typical fractures obtained in station \#2 and station \#4. The numbers in the pictures represent the distance from the borehole surface to the fracture location and the fractures were extracted by the greyscale of the pixel in the picture. $P$ and $A$ values from each figure can be estimated and used for the calculation of $C$ values of each crack.

By analyzing the circularity $C$ values of the surrounding rock fractures in each borehole, the extent of the loose zone and degree of fracture can be measured at station $\# 2$.

In Figure 14, the $x$-axis is the distance of the crack from the borehole, and the $y$-axis is the circularity $C$ value of the crack at this point.

As depicted in Figure 14, there are spaces between the columns of data, indicating that the cracks are not evenly distributed and $C$ values of cracks of the surrounding rock at different depths are different. Maximum $C$ values appear at different locations. Interestingly, $C$ values at deeper locations from the roof are higher than those of the loose zone. Results here show that at different depths, the crushing zone and elastic zone were not adjacent to each other, which may be due to the zonal disintegration in the surrounding rock.

Based on the results from station \#1, it can be observed that the distribution of $C$ values is similar to station \#2, although fractures are less dense. In conjunction with the deformation behavior of the surrounding rock, it is known that many fractures and compression occur at deep roadway under high dynamic pressure [17]. Thereby, the crushing zones gradually develop and get wider, such that the rock mass between these zones are compressed.

Through field measurement and analysis, it can be seen that due to the longwall retreatment, the surrounding stress state is continuously changing, where the surrounding rock also deforms accordingly. However, at different depths, the stress state, fracture development, and deformation are significantly different. Since the fracture initiation and development cannot be monitored at all times, further investigation is carried out via numerical modeling. 


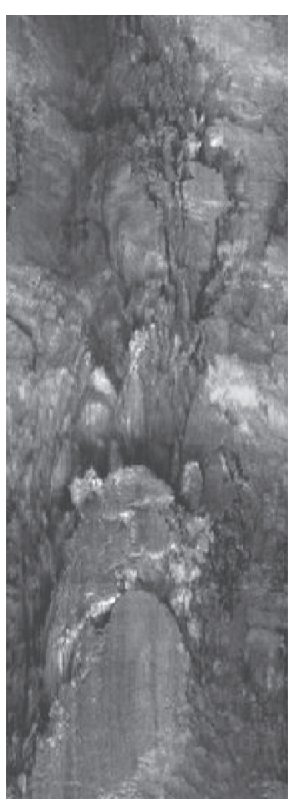

(a)

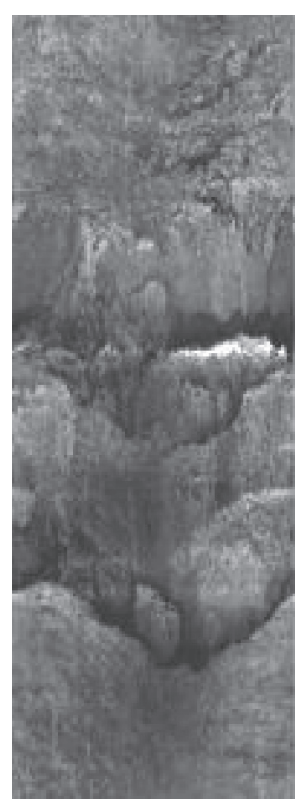

(b)

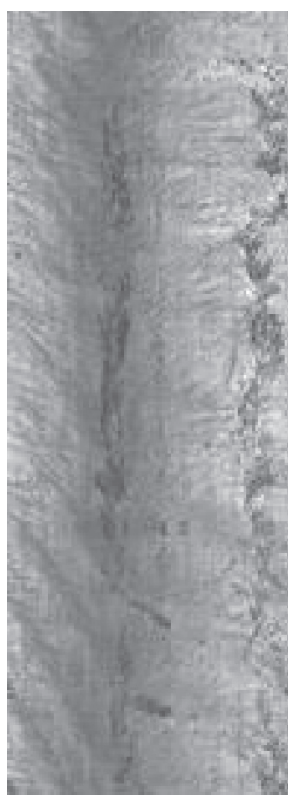

(c)

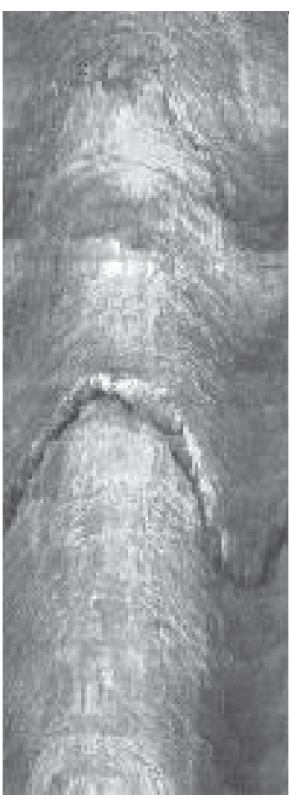

(d)

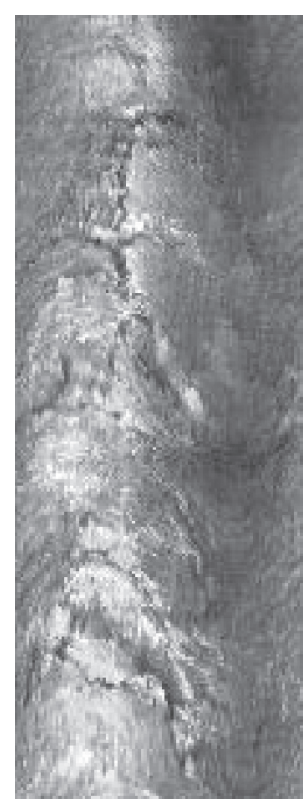

(e)

FIGURE 10: Crack types in the surrounding rock of the roadway: (a) crushing area; (b) circumferential crack; (c) longitudinal crack; (d) oblique crack; (e) various cracks.

(1)

$0.0 \mathrm{~m} \quad 1.0 \mathrm{~m} \quad 2.0 \mathrm{~m} \quad 3.0 \mathrm{~m} \quad 4.0 \mathrm{~m} \quad 5.0 \mathrm{~m} \quad 6.0 \mathrm{~m} \quad 7.0 \mathrm{~m} \quad 8.0 \mathrm{~m} \quad 9.0 \mathrm{~m}$

(1)

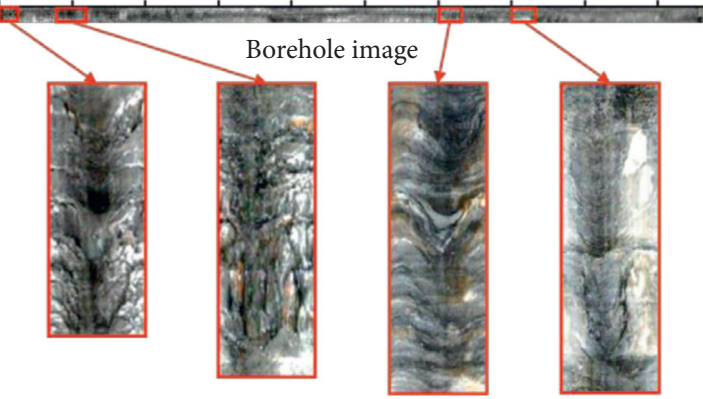

FIGURE 11: Borehole imaging of borehole \#4 at station \#1 under the influence of excavation,:(1) the $2 \mathrm{D}$ view of the borehole from 0 to $360^{\circ}$; (2) the zoomed-in views of selected sections.

(1)

$0.0 \mathrm{~m} \quad 1.0 \mathrm{~m} \quad 2.0 \mathrm{~m} \quad 3.0 \mathrm{~m} \quad 4.0 \mathrm{~m} 5.0 \mathrm{~m} \quad 6.0 \mathrm{~m} \quad 7.0 \mathrm{~m} \quad 8.0 \mathrm{~m} \quad 9.0 \mathrm{~m}$

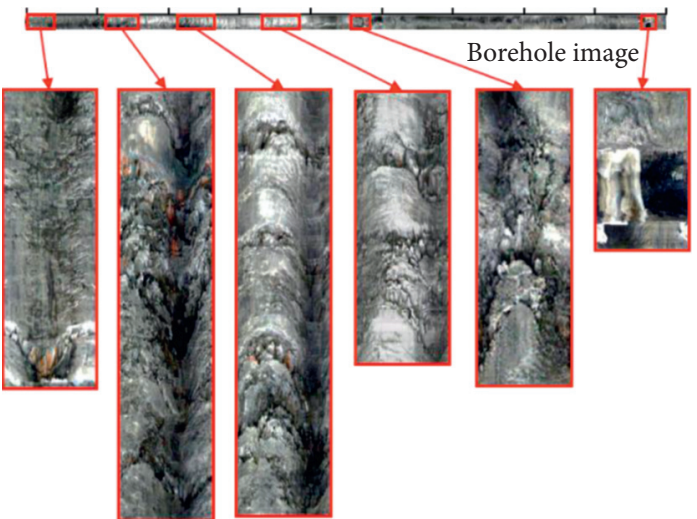

FIGURE 12: Borehole imaging of borehole \#4 at station \#2 under the influence of longwall retreatment: (1) the $2 \mathrm{D}$ view of the borehole from 0 to $360^{\circ}$; (2) the zoomed-in views of selected sections.

\section{Numerical Simulation}

To better simulate the crack distribution and development of the surrounding rock under the influence of dynamic pressure, the simulation used the 3D global and discrete element $2 \mathrm{D}$ local combination model. The principal stress in the direction of the roadway ahead of the longwall face was extracted from the global model and then used as the boundary stress of the $2 \mathrm{D}$ model.

The stress at the deep roadway is generally calculated based on the depth of cover and the empirical equation. Whittanker and Potts [18] studied the stress around the longwall face and found that the vertical stress ahead of the longwall face increases first and then decreases to the original stress level as the distance from the face increases.

Compared with the theoretical analysis, the discrete element 3D model can better simulate the distribution and development of surrounding rock cracks during excavation. However, to accurately model the fracture development, the particle size in the numerical model must be very small. This means that a significant number of particles are required to construct the model, which makes the computation time too long. On the other hand, if a 2D model is implemented, the particle size can be reduced while keeping the calculation time short. Thus, the global-local model can yield better simulation results on the influence of longwall retreatment on the fracture development around the roadway.

4.1. Rock Mass and Material Properties. To determine the rock properties at different layers, the geological strength index (GSI) method was used. According to the ISRM standard, rock samples obtained from the mine site were analyzed to obtain the density, uniaxial compressive strength 


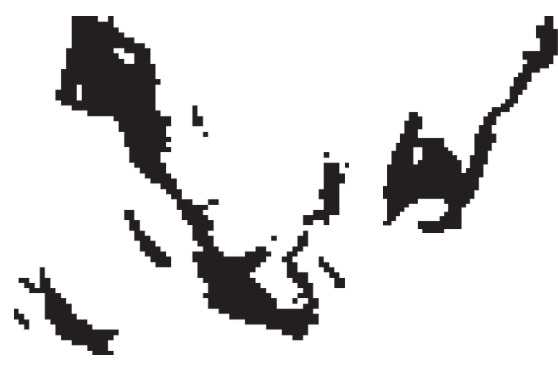

(a)

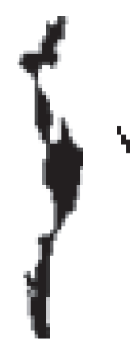

(c)

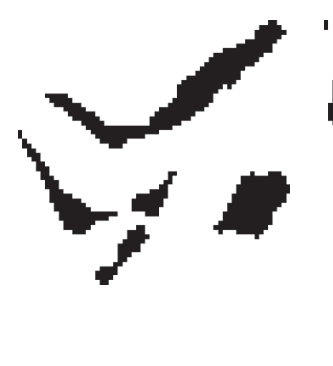

(d)

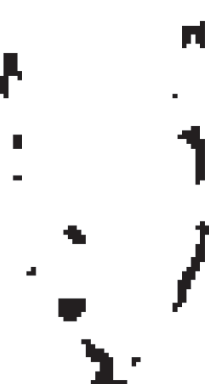

(e)

FIGURE 13: Crack characteristics: (a) $0.12 \mathrm{~m}$, (b) $1.56 \mathrm{~m}$, (c) $2.42 \mathrm{~m}$, (d) $6.12 \mathrm{~m}$, and (e) $7.13 \mathrm{~m}$.

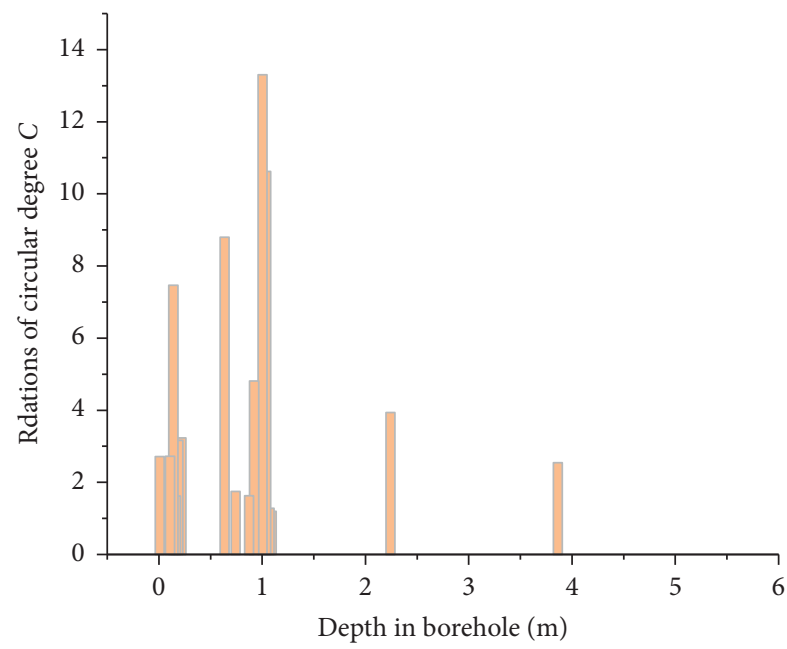

Rdations of circular degree $C$

(a)

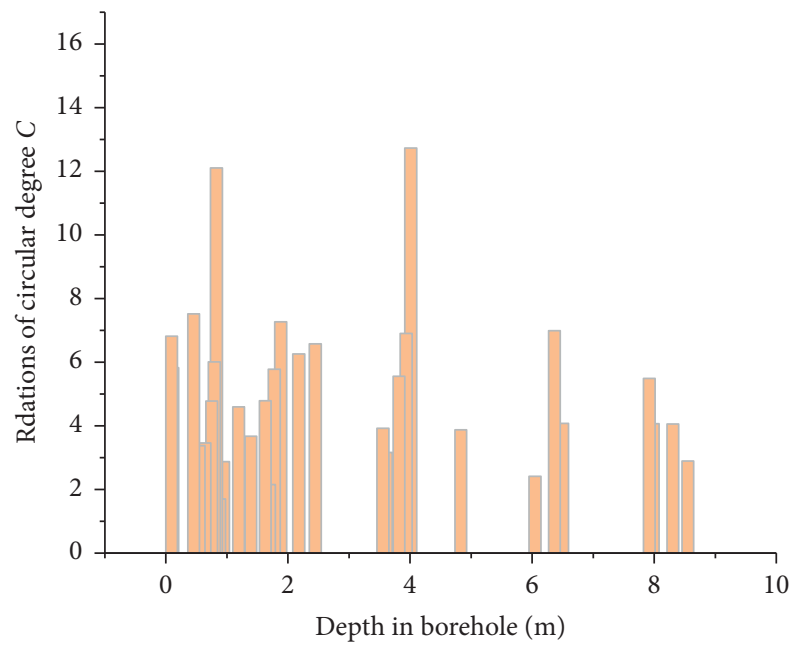

Rdations of circular degree $C$

(c)

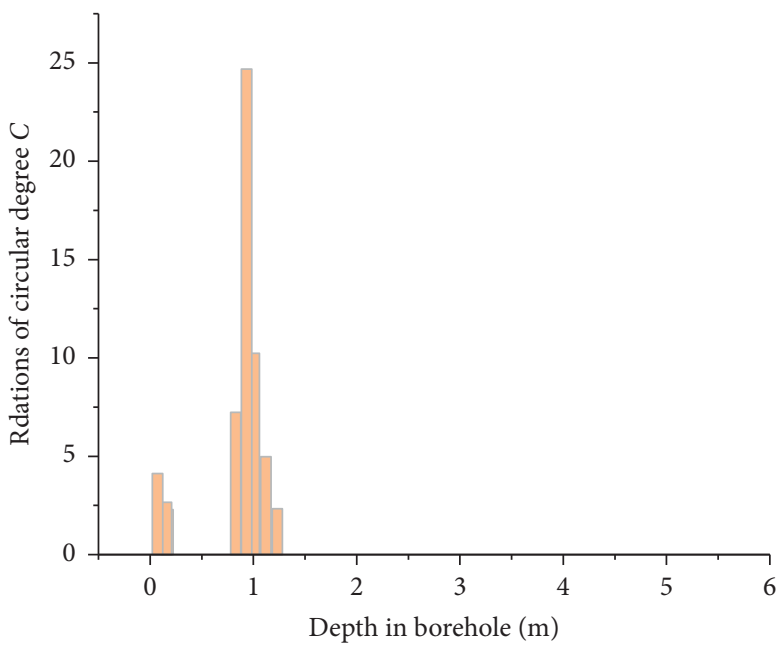

Rdations of circular degree $C$

(b)

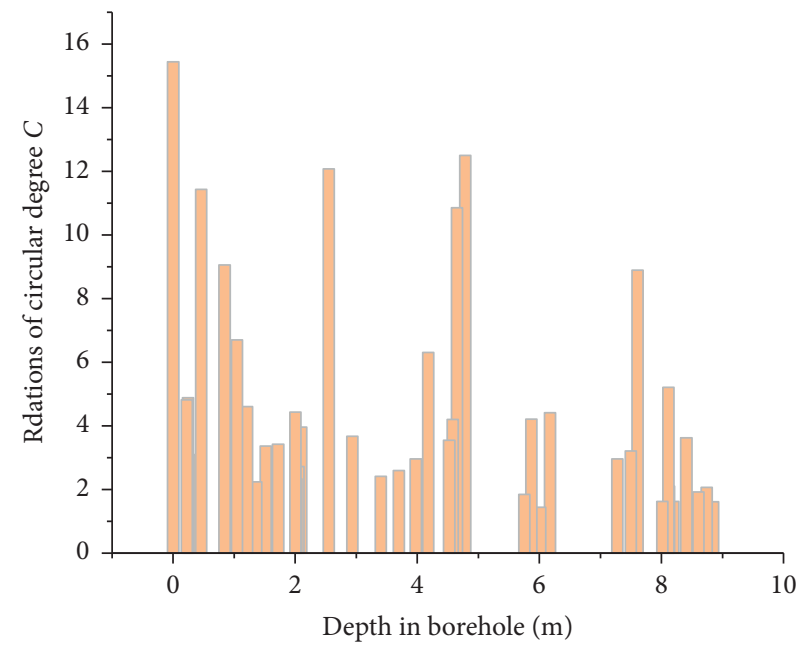

Rdations of circular degree $C$

(d)

Figure 14: Continued. 


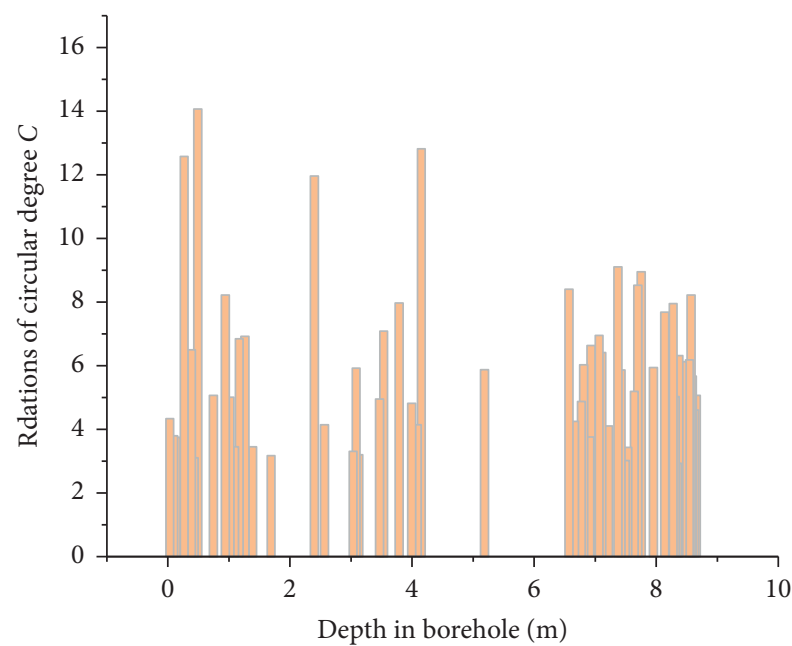

Rdations of circular degree $C$

(e)

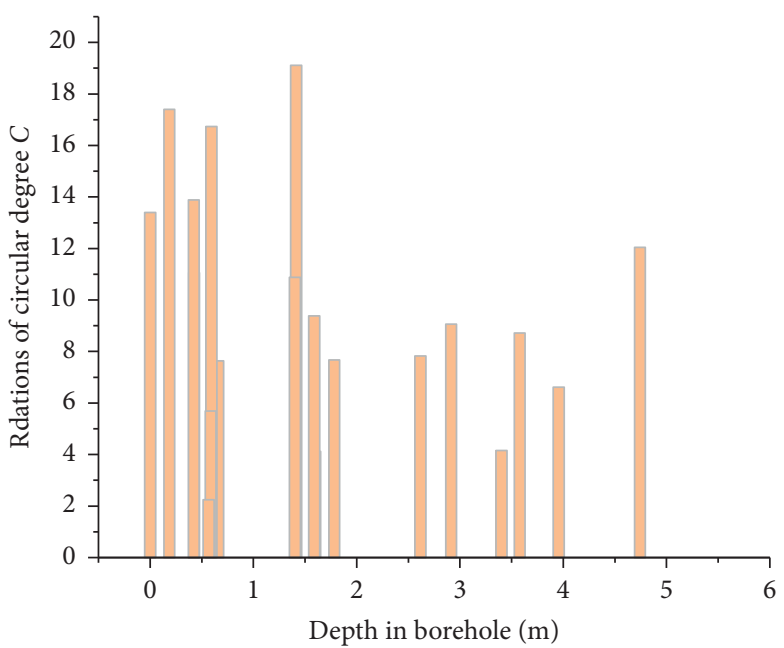

Rdations of circular degree $C$

(f)

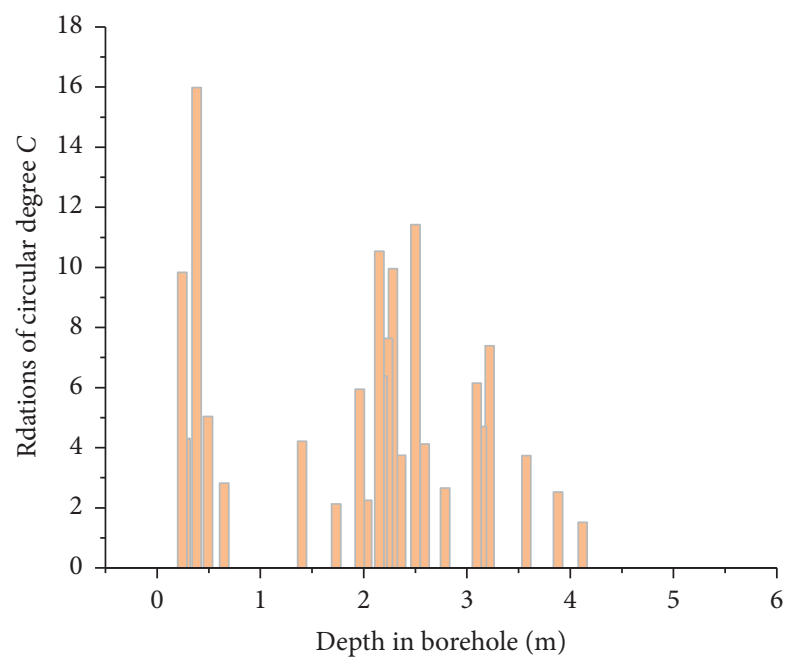

Rdations of circular degree $C$

(g)

Figure 14: The distribution of $C$ value at various borehole depths: (a) borehole \#1 at station \#2; (b) borehole \#2 at station \#2; (c) borehole \#3 at station \#2; (d) borehole \#4 at station \#2; (e) borehole \#5 at station \#2; (f) borehole \#6 at station \#2; (g) borehole \#7 at station \#2.

$\sigma_{c i}$, internal friction angle $\Phi, m_{i}$, Poisson's ratio $\mu$, and elastic modulus $E_{i}$; see Table 1 . However, due to the preexisting defects (such as joints, cracks, bedding, and different mineral compositions) in the rock mass, the strength of the rock mass is lower than the rock strength measured in the laboratory. Therefore, the specimen strength was converted to the rock mass strength [19]. The elastic modulus $E_{\text {mass }}$ was then calculated using the empirical formula proposed by Hoek and Diederichs [20]. The value of GSI was determined according to the latest GSI value table [21], which gives the GSI reference value according to the rock type.

$$
E_{\text {mass }}=E_{i}\left(0.02+\frac{1-(D / 2)}{1+e^{(60+15 D-G S I / 11)}}\right) \text {. }
$$

In the table, $D$ which is the disturbance factor is assumed to be 0 according to the actual situation of the project. The calculation results are shown in Table 1.

4.2. 3D Global Model: FLAC3D. The FLAC3D with MohrCoulomb constitutive model was used for stress analysis ahead of the longwall face. The layout of the model can be seen in Figure 15. Since the monitoring stations were far away from the initial gas drainage roadway, the model only simulated the longwall face within the $300 \mathrm{~m}$ from the monitoring stations. The numerical longwall face is $300 \mathrm{~m}$ in length and $350 \mathrm{~m}$ in width, at the height of $177 \mathrm{~m}$. To better simulate the stress around the gob area, the low stiffness material was selected during model construction rather than 
TABLE 1: Rock material and mass properties.

\begin{tabular}{|c|c|c|c|c|c|c|c|c|c|}
\hline \multirow{2}{*}{ Lithology } & \multicolumn{4}{|c|}{ Rock specimens properties } & \multicolumn{5}{|c|}{ Rock mass properties } \\
\hline & $m_{i}$ & Density $\left(\mathrm{kg} / \mathrm{m}^{3}\right)$ & Poisson's ratio & $E_{i}(\mathrm{GPa})$ & GSI & $c(\mathrm{MPa})$ & $T_{c i}(\mathrm{MPa})$ & $\Phi(\mathrm{deg})$ & $E_{\text {mass }}$ \\
\hline Mudstone & 5 & 2773 & 0.12 & 17.5 & 45 & 11.74 & 3.73 & 18.66 & 3.91 \\
\hline Siltstone & 9 & 2680 & 0.2 & 19.5 & 65 & 3.75 & 1.84 & 38 & 12.32 \\
\hline Sandstone & 19 & 2681 & 0.26 & 56 & 35 & 11.74 & 6.87 & 18.66 & 6.35 \\
\hline 13-1 Coal & 14 & 1329 & 0.36 & 17.5 & 30 & 4.57 & 1.63 & 35.21 & 1.42 \\
\hline Sandy mudstone & 6 & 2510 & 0.15 & 10.85 & 29 & 2.45 & 2.01 & 40 & 0.83 \\
\hline Medium sandstone & 15 & 2580 & 0.2 & 5.99 & 60 & 4 & 1.2 & 37 & 3.11 \\
\hline Fine sandstone & 17 & 2873 & 0.15 & 10.85 & 55 & 3.75 & 1.84 & 3.75 & 4.43 \\
\hline
\end{tabular}

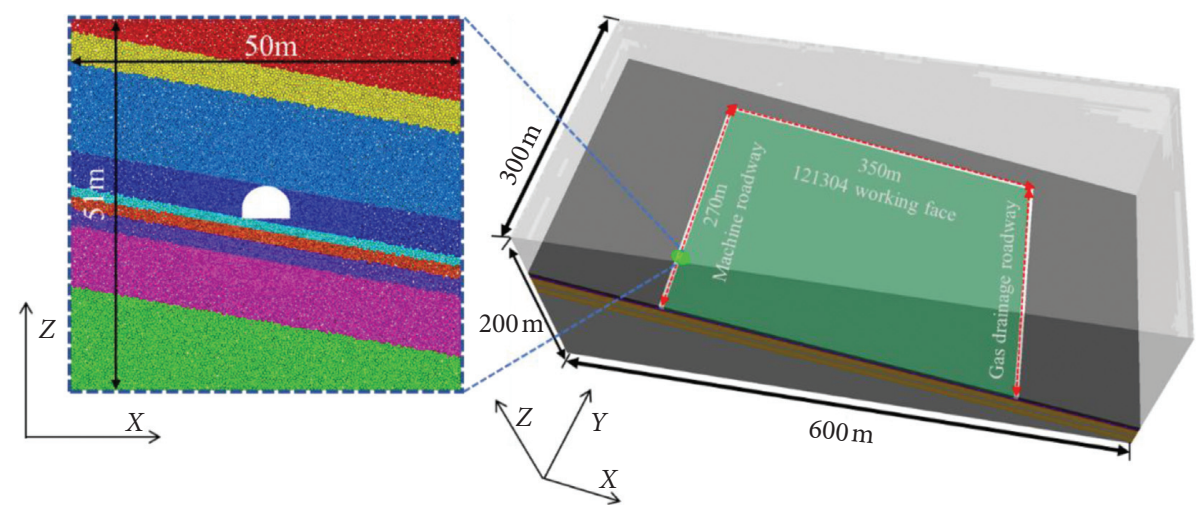

FIGURE 15: Global-local model.

a blank space. Kose and Cebi [22] suggested that the elastic modulus of the material at gob is generally $15 \sim 3500 \mathrm{MPa}$. The elastic modulus has a great influence on the stress behind the longwall face, but it has less influence on the coal to be recovered [23]. As this study only focused on the section of the roadway where the coal was yet to be recovered, the elastic modulus of this part of the mesh was set to $250 \mathrm{MPa}$, and Poisson's ratio was set to 0.25 .

The bottom boundary of the model is fixed and the top boundary is free to move, whereas the other four boundaries can only roll in a vertical direction. According to the depth of cover of the upper boundary of the model, vertical stress of 17.35 $\mathrm{MPa}$ was applied, and the stress coefficient was calculated according to the shallow crustal stress in the Chinese mainland [24]:

$$
\begin{gathered}
0.6 \leq \frac{\sigma_{H}}{\sigma_{V}} \leq \frac{1550}{H}+0.6, \\
k=\frac{190.3}{H}+1.0399,
\end{gathered}
$$

where $\sigma_{H}$ is the maximum horizontal principal stress, $\sigma_{V}$ is the vertical stress, $\mathrm{H}$ is the depth of cover, and $k$ is the stress coefficient. Given $800 \mathrm{~m}$ depth of cover of the roadway, equation (4) estimated the $k$ value to be 1.28 .

Based on different rock strata, the mechanical properties are also different (Table 1). Gravity was applied to the model and the model was processed until the equilibrium was reached. The space behind the longwall was then replaced with the selected soft material. The boundary stress of the $2 \mathrm{D}$ model was recorded from the measuring point, which was $150 \mathrm{~m}$ away from the longwall face. From Figure 16, it can be seen that during longwall retreatment, the maximum stresses in $z$ and $x$ directions around the roadway reached 20.6 $\mathrm{MPa}$ and 26.89 $\mathrm{MPa}$, respectively. Also, the maximum stresses in $z$ and $x$ directions during roadway excavation reached $16.42 \mathrm{MPa}$ and $21.87 \mathrm{MPa}$.

4.3. 2D Local Model: PFC. Due to the discontinuity of rock materials (such as joints, cracks, bedding, and different mineral compositions), some problems have arisen when using continuous media mechanics to analyze rock material properties. Compared with the finite element model (FEM), the particle flow discrete element model (DEM) can provide more reliable simulations on the nonlinear mechanical phenomena of rock fragmentation and deep roadway, especially the distribution and development of cracks in the surrounding rock of deep roadway. In this paper, the FlatJoint Model (FJM) proposed by Potyondy [25] was used. Figure 17 is a schematic diagram of the FJM (2D). An interface is created between two particles while particles on both sides of the surface are in contact with the surface. At the same time, this interface is divided into multiple elements and each element can be either bonded or unbonded. Although the breakage of the bonding unit causes local damage to the interface, the interface can still resist bending moments. Based on this microproperty, the FJM can overcome the three shortcomings of the Bonded-Particle Model [26]: (1) the ratio between $\sigma_{c i}$ and tensile strength $\left(\sigma_{t}\right)$ being smaller than the laboratory results, (2) the extremely low $\Phi$, and (3) the linearity of strength envelope. By using FTM, more realistic macromechanical properties of the rock can be constructed. Since PFC uses a contact model and does 


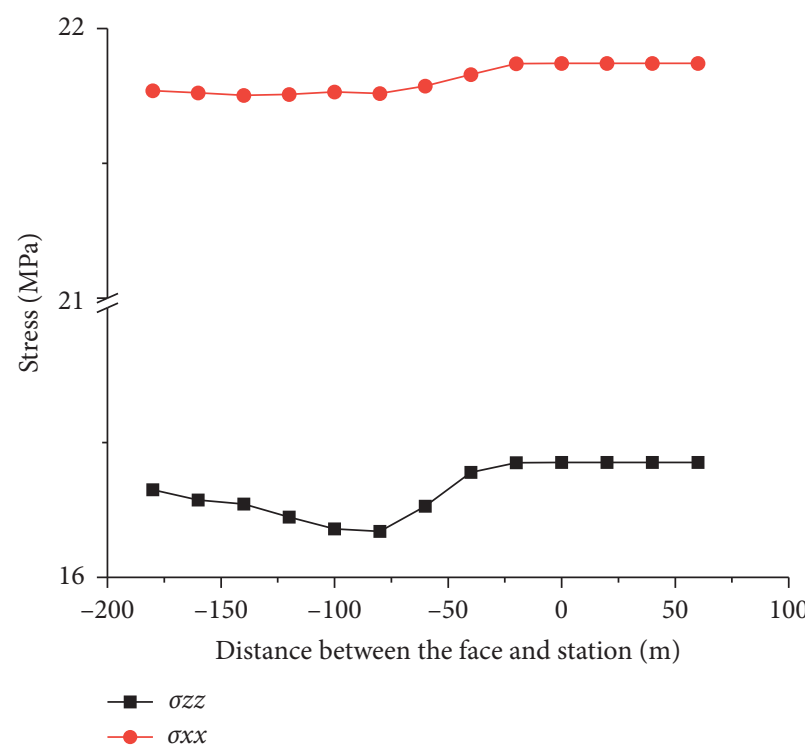

(a)

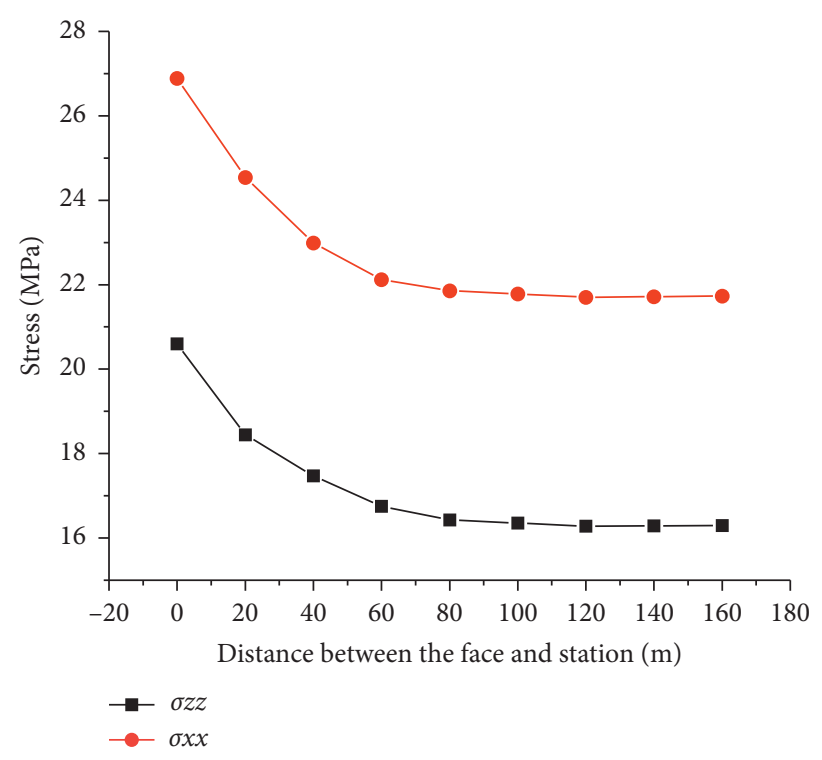

(b)

Figure 16: Local model stress conditions from the global model: (a) roadway excavation; (b) longwall retreatment.

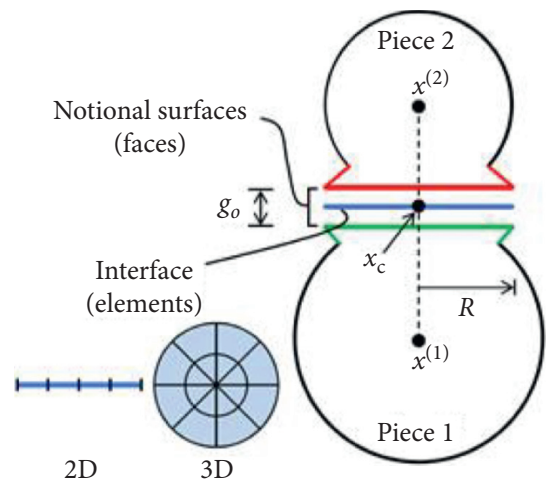

(a)

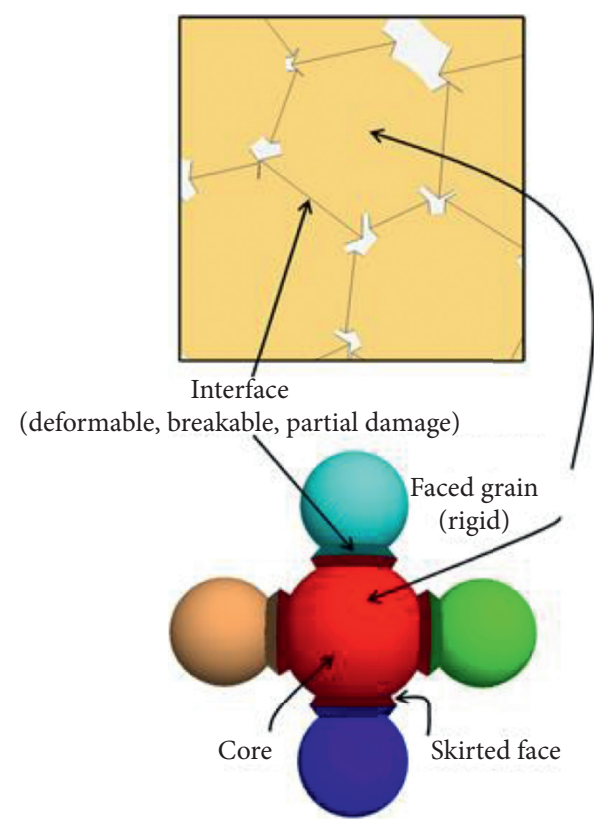

(b)

FIGURE 17: Flat-joint contact (left) (a) and flat-jointed material (right) (b) [26].

not have a suitable constitutive model to reflect the macroscopic mechanical parameters of the rock, it is necessary to calibrate its microparameters to characterize the macroproperties of the rock mass [25].

4.4. Model Calibration. For brittle rock, the appropriate methodology to use microparameters to describe the macroproperties remains a concern in the field of geotechnical engineering. Currently, the common way is to calibrate the microparameters against the macroproperties collected from experimental results, so that the synthetic rock sample is similar to the actual rock sample from the field.

The mechanical properties of rock can be obtained by the uniaxial compressive tests, including the peak strength $\sigma_{u}$, elastic modulus $E, \sigma_{t}$, and $\mu$; see Table 2 . For the sake of simplicity, only $E_{c}, k_{n} / k_{s}, c$, and $\sigma_{c}$ are generally modified during the calibration process [26]. $E_{c}$ is the effective 
TABLE 2: Macroparameter and microparameter calibration.

\begin{tabular}{lcccccccccc}
\hline \multirow{2}{*}{ Lithology } & \multicolumn{4}{c}{ Microparameter } & \multicolumn{4}{c}{ Macroparameter } \\
& Density $\left(\mathrm{kg} / \mathrm{m}^{3}\right)$ & $E_{\mathrm{c}}(\mathrm{GPa})$ & $k_{\mathrm{n}} / k_{\mathrm{s}}$ & $\sigma_{\mathrm{c}}(\mathrm{MPa})$ & $t_{\mathrm{c}} / \sigma_{\mathrm{c}}$ & $\sigma_{u}(\mathrm{MPa})$ & $\sigma_{t}(\mathrm{MPa})$ & $E(\mathrm{GPa})$ & $\mu$ & $\mathrm{UCS} / \mathrm{TS}$ \\
\hline Coal & 1329.3 & 17.5 & 10 & 3.06 & 8.22 & 12.68 & 1.64 & 15.46 & 0.36 & 7.75 \\
Mudstone & 2773 & 21.81 & 1.5 & 5.79 & 21.29 & 37.87 & 3.74 & 26.26 & 0.12 & 10.13 \\
Sandstone & 2680.9 & 56 & 3.4 & 12.97 & 54.29 & 91.98 & 6.87 & 57.7 & 0.26 & 13.39 \\
\hline
\end{tabular}

modulus of the bond, $k_{n} / k_{s}$ is the stiffness ratio of the bond, ${ }_{c}$ is the cohesion of the bond, and $\sigma_{c}$ is the tensile strength of the bond.

In summary, a standard rock model with a width of $50 \mathrm{~mm}$ and a height of $100 \mathrm{~mm}$ was constructed in PFC. The process involves (i) creation of walls at the boundaries of the rectangular, (ii) generation of particles at the radius from 0.3 to $0.5 \mathrm{~mm}$ within the walls until the porosity reaches 0.1 , (iii) assigning FJM parameters to particle contacts, and (iv) a servo-control mechanism [27] used to conduct the uniaxial compressive test and direct tension test. There are 8773 particles generated in a rock sample, as displayed in Figure 18.

The uniaxial compression calibration was carried out according to the ISRM standard, with a loading speed of $0.1 \mathrm{~mm} / \mathrm{min}$. The axial strain $x_{1}$ and the transverse strain $x_{2}$ of the model were determined by recording displacements of the upper and lower walls and the gauge particles in the middle of the model, respectively. The average force of the upper and lower walls was recorded to determine the load F.

Based on the procedures which were suggested by WU [26], the calibrations of sandstone, mudstone, and coal were achieved. The proposed calibration process includes the following:

(1) UCS/TS was satisfied by changing $\tau_{c} / \sigma_{c}$

(2) $E$ and $\mu$ were calibrated by $E_{c}$ and $k_{n} / k_{s}$

(3) $\sigma_{c}$ was initially determined by the direct tension test and then matched with $\sigma_{t}$

(4) ${ }_{c}$ was modified to ensure that $\sigma_{u}$ was reached

According to the process, the microparameters were obtained; see Table 2. The stress-strain curve is displayed in Figure 18. The similarity between the simulation results and the laboratory results was over 95\%, suggesting that calibrations can be used for roadway model generation.

4.5. Simulation of 121304 Longwall Panel. The 121304 longwall panel was constructed by using PFC (2D), as shown in Figure 19. The model dimensions are $51 \times 50 \mathrm{~m}^{2}$ and it contains 112,684 particles. Smaller radius particles were generated in the area of interest to study the rock behavior in detail, whereas larger radius particles were generated near the boundaries to reduce the computation time. The radius of the particle was dependent on its location, i.e., the distance of the particle from the center of the roadway; see Figure 20 and Table 3 . The ratio between Rmax and the radius of section $(R), R_{\max } / R$, was kept at 200 to ensure the consistency of the model between different rock strata. The vertical stress was applied on the top wall, while the horizontal stress was applied on the sidewall. The vertical displacement of the bottom wall was constrained. The gravity was also applied to simulate the field scenario closely. By deleting particles progressively, the roadway excavation could be mimicked; see Figure 19. Also, biaxial loading was applied to simulate the roadway excavation and longwall retreatment.

As shown in Figure 19, the dip angle of the rock formation is $11^{\circ}$ and the position of the roadway is in line with the field situation. Dimensions of the roadway excavation are the same as the real conditions. The section is a semicircular arch with straight walls. The arch radius is $3.1 \mathrm{~m}$, the height of the two ribs is $1.1 \mathrm{~m}$, and the width is $6.2 \mathrm{~m}$.

\section{Simulation Results for Fracture Development}

In field cases, it has been approved that the roadway instability is directly related to the fracture development in the surrounding rock. Through PFC23, the generation and development of cracks in the roadway excavation and longwall retreatment can be well studied. Figures 21(a) 21(c) show the excavation process, while Figures 21 (d) 21(f) illustrate the retreatment process. In the figure, the purple color represents a tensile crack while the red color is a shear crack.

According to Figure 21, it can be observed that after the roadway excavation, tensile cracks dominated around the roadway. Tensile cracks initially formed at the surface of the roadway and propagated toward deeper locations. However, the overall development direction of fractures is consistent with the trend of rock strata. This is because different rocks have different lithologies, and fractures are preferred to develop in weak rocks.

Due to the disturbance of longwall retreatment, the fracture development and crushing zone are significantly greater than those of the roadway excavation. Tensile cracks developed from the ribs and propagated outwards in the horizontal direction and shear cracks later formed in the deeper locations. With the stress relaxation due to fracturing, both roof and floor also experienced shear failure and eventually formed a pair of shear planes above the top of the roof. The shear planes also developed in different directions, which resulted in the net-like crushing zone. This agrees with results from the field observation and the numerical simulation of Gao [28].

The contact force chain is the interaction force between the contact particles. As shown in Figure 22, the greater the contact force, the darker the force chain color. After the excavation of the section, the failure of two ribs caused the stress to be released rapidly; see Figure 22(b). This led to the stress release at the roof and floor of the roadway, which redistributes the contact force to deeper locations; see Figure 22(c). The contact 


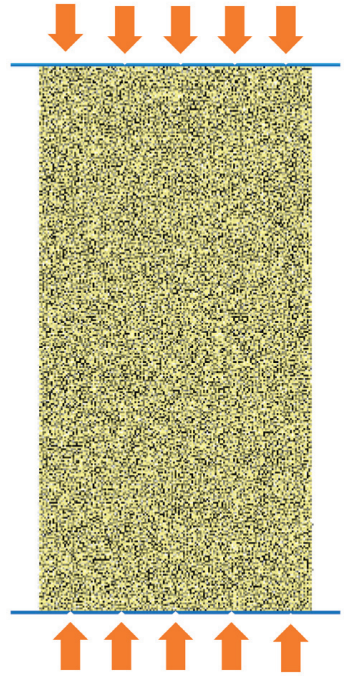

(a)

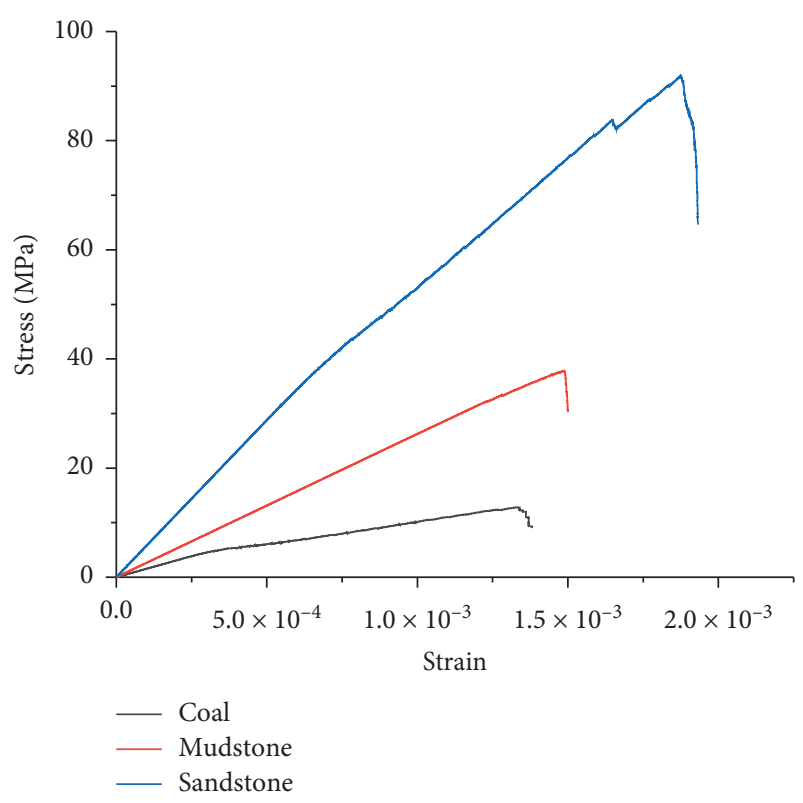

(b)

Figure 18: Simulated uniaxial compressive test (left) (a) and stress-strain curves for the rock (right) (b).

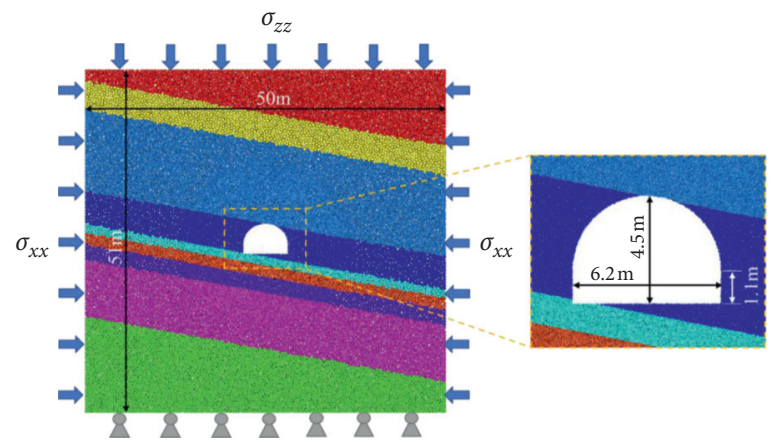

FIgURE 19: Numerical model for the surrounding rock of working face machine lane.

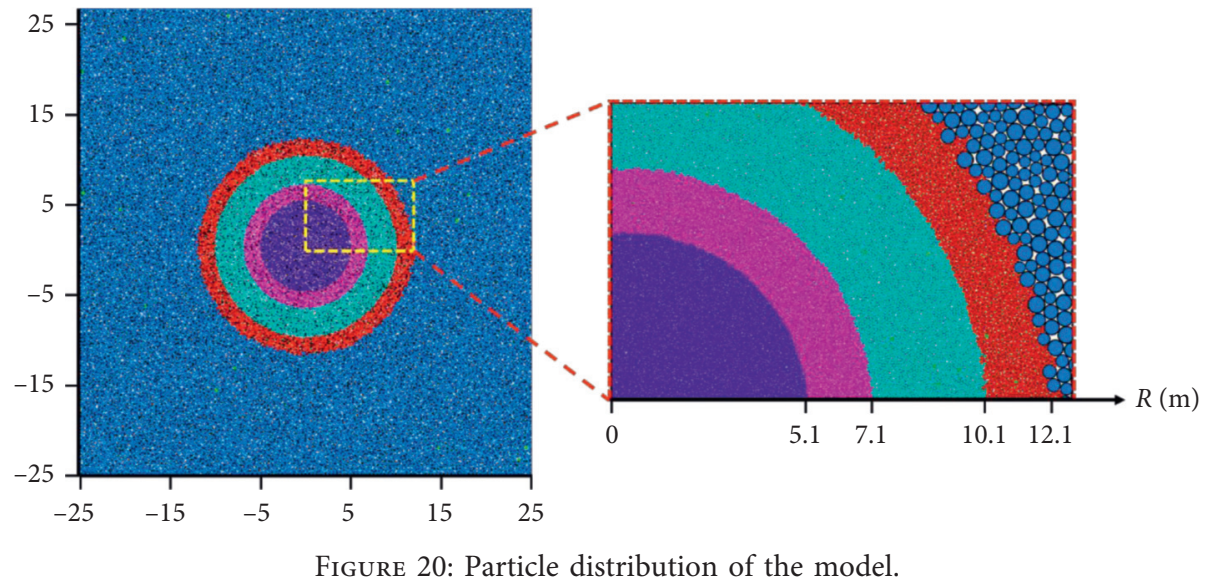

force within the rock depends on the rock strata so that that internal contact force is different layer by layer. Finally, the fracture degree of the surrounding rock is relatively high, which means that the contact force between the particles is almost zero. This indicates that the ultimate bearing capacity of the surrounding rock is negligible. 
TABle 3: Particle radius and distribution.

\begin{tabular}{lccccc}
\hline Distribution range $(\mathrm{m})$ & $0 \sim 5.1$ & $5.1 \sim 7.1$ & $7.1 \sim 10.1$ & $10.1 \sim 12.1$ & $12.1 \sim$ boundary \\
\hline Particle radius $(\mathrm{cm})$ & $1.5 \sim 2.25$ & $2.1 \sim 3.55$ & $3.6 \sim 5.05$ & $3.9 \sim 6.05$ & $15.9 \sim 25.5$ \\
\hline
\end{tabular}

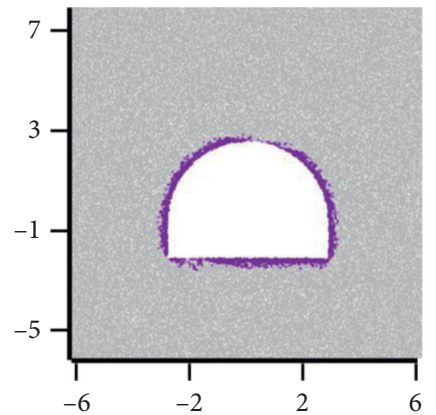

(a)

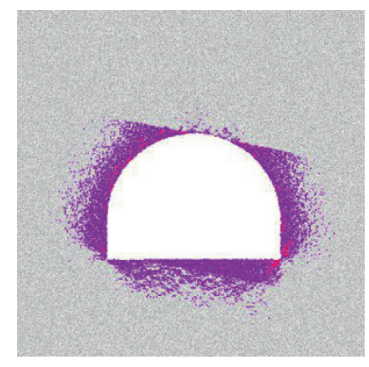

(b)

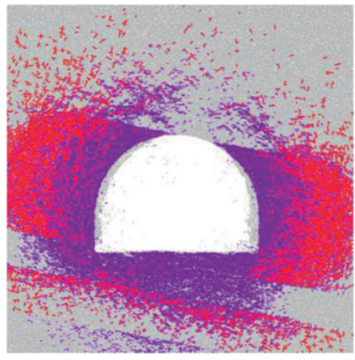

(e)

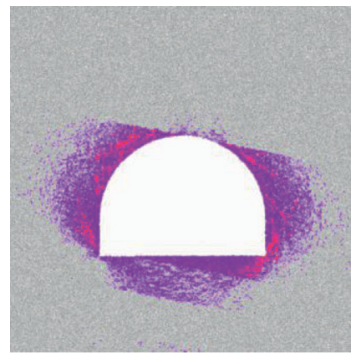

(c)

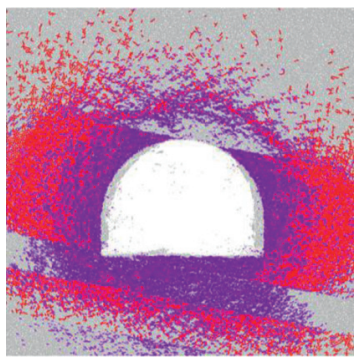

(f)

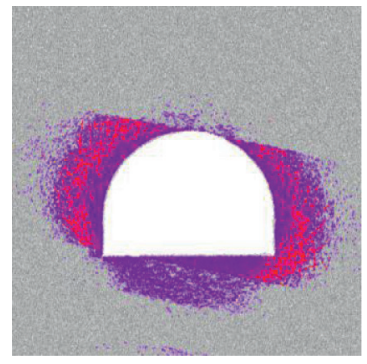

(d)

Figure 21: The fracture distribution during roadway excavation and longwall retreatment.

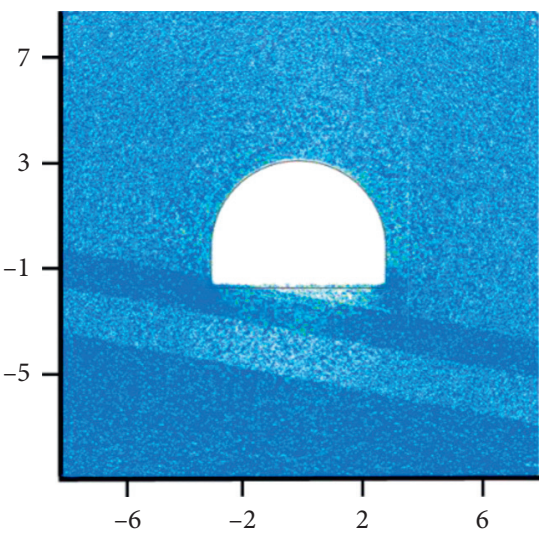

(a)

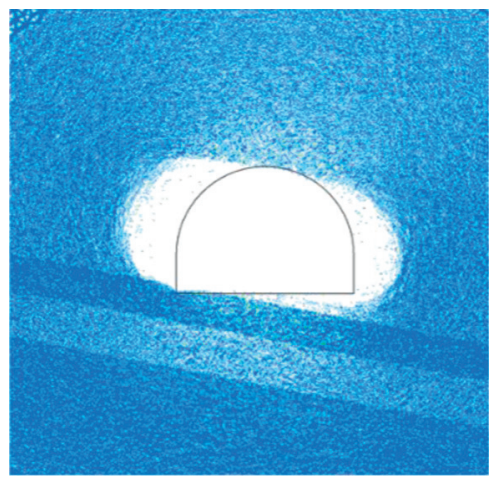

(b)

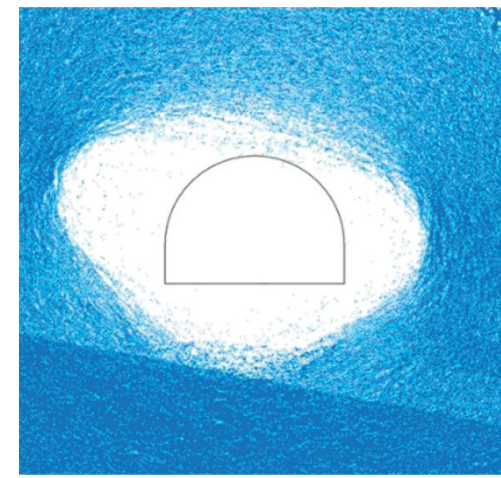

(c)

Figure 22: The contact force chain distribution during longwall retreatment.

\section{Conclusions}

In this paper, the mechanism of crack initiation and development under the influence of dynamic pressure in deep soft rock roadway are studied. The 121304 longwall face at Kouzidong coal mine has a typical deep soft rock roadway, which was under the impact of the roadway excavation and the longwall retreatment. Based on the borehole imaging and displacement monitoring results, the fracture development and distribution under the dynamic pressure were analyzed. The mechanical properties of rock samples were collected from the laboratory tests and downgraded by GSI to obtain the rock mass properties. FLAC3D was used to determine the stress conditions for the PFC2D model during roadway excavation and longwall retreatment. The microparameter calibration process was also discussed in the paper.

Based on the field monitoring results, it can be seen that the deformation of surrounding rock continuously increased 
under the influence of dynamic pressure. Thereby, the stress state, fracture development, and deformation are considerably different at different depths.

A PFC2D model was constructed based on the geological conditions of the longwall face. By applying different stress conditions, fracture development and stress redistribution under different scenarios were successfully replicated and analyzed.

Based on the results of field monitoring and numerical simulation, the mechanism and evolution of fracture development around deep soft rock roadway under dynamic pressure were revealed. Cracks first appeared in the shallow surrounding rock around the roadway and propagated toward the deeper soft rock layer due to the excavation-induced stress redistribution. Thereby, rock around the ribs also experienced stress relaxation while tensile cracks dominated around the roadway. Under dynamic pressure, cracks continuously propagated toward the soft rock layer. However, the failure mechanism transformed from tensile to shear failure. Due to the stress relaxation of ribs, the roadway roof also failed and a pair of large shear failure planes intersected above the roof. The rock mass between the roof and the shear planes is competent and unbroken. At the same time, the stress relaxation zone kept expanding and high-stress concentration shifted to the deep section of the surrounding rock.

\section{Data Availability}

The data used to support the findings of this study are included within the article.

\section{Conflicts of Interest}

The authors declare that they have no conflicts of interest.

\section{Acknowledgments}

The authors would like to show gratitude to all those who have helped them during the writing of this paper. This research was funded by the National Key Research and Development Plan (Grant no. 2017YFC0603001) and the State Key Laboratory of Coal Resources and Safe Mining, China University of Mining and Technology (no. SKLCRSM15X01).

\section{References}

[1] L. Xu, K. Lu, Y. Pan, and Z. Qin, "Study on rock burst characteristics of coal mine roadway in china," Energy Sources Part A-Recovery Utilization And Environmental Effects, vol. 2019, pp. 1556-7036, 2019.

[2] H. Wagner, "Deep mining: a rock engineering challenge," Rock Mechanics and Rock Engineering, vol. 52, no. 5, pp. 1417-1446, 2019.

[3] X. Li, F. Gong, M. Tao et al., "Failure mechanism and coupled static-dynamic loading theory in deep hard rock mining: a review," Journal of Rock Mechanics and Geotechnical Engineering, vol. 9, no. 4, pp. 767-782, 2017.

[4] M. Gao, W. Jin, R. Zhang, J. Xie, B. Yu, and H. Duan, "Fracture size estimation using data from multiple boreholes,"
International Journal of Rock Mechanics and Mining Sciences, vol. 86, pp. 29-41, 2016.

[5] M. Bo, J. Hongwen, C. Kunfu, and H. Su, "Failure mechanism and stability control of a large section of very soft roadway surrounding rock shear slip," International Journal of Mining Science and Technology, vol. 23, no. 1, pp. 127-134, 2013.

[6] Q. Tang, W. Xie, X. Wang, Z. Su, and J. Xu, "Numerical study on zonal disintegration of deep rock mass using three-dimensional bonded block model," Advances in Civil Engineering, vol. 2019, Article ID 3589417, 12 pages, 2019.

[7] A. Lisjak, D. Figi, and G. Grasselli, "Fracture development around deep underground excavations: insights from FDEM modelling," Journal of Rock Mechanics and Geotechnical Engineering, vol. 6, no. 6, pp. 493-505, 2014.

[8] Z. Ma, Y. Jiang, W. Du, Y. Zuo, and D. Kong, "Fracture evolution law and control technology of roadways with extra thick soft roof," Engineering Failure Analysis, vol. 84, pp. 331-345, 2018.

[9] F. Gao and D. Stead, "Discrete element modelling of cutter roof failure in coal mine roadways," International Journal of Coal Geology, vol. 116, pp. 158-171, 2013.

[10] M. Cai, P. K. Kaiser, H. Morioka et al., "FLAC/PFC coupled numerical simulation of $\mathrm{AE}$ in large-scale underground excavations," International Journal of Rock Mechanics and Mining Sciences, vol. 44, no. 4, pp. 550-564, 2007.

[11] C. Edelbro, "Numerical modelling of observed fallouts in hard rock masses using an instantaneous cohesion-softening friction-hardening model," Tunnelling and Underground Space Technology, vol. 24, no. 4, pp. 398-409, 2009.

[12] J. Sjöberg and L. Malmgren, "Application of global-local modelling to mining rock mechanics problems," in Proceedings of the First International FLAC/DEM Symposium on Numerical Modeling, pp. 25-27, Minneapolis, MN, USA, August 2008.

[13] F. Dong, Support Theory Based on the Broken Rock Zone in Surround Rock, China Coal Industry Publishing House, Beijing, China, 2001.

[14] M. Cai and P. K. Kaiser, "Assessment of excavation damaged zone using a micromechanics model," Tunnelling and Underground Space Technology Incorporating Trenchless Technology Research, vol. 20, no. 4, pp. 301-310, 2005.

[15] J. Hongwen, L. Yuanhan, and L. Junqi, "Borehole camera technology for measuring the relaxation zone of surrounding rock:mechanism and application," Journal of China University of Mining \& Technology, vol. 38, no. 5, pp. 645-649, 2009.

[16] C. Changxiu and J. Qiong, "Algorithm of circle analyse in image processing," Journal of Chongqing University (Natural Science Edition), vol. 28, no. 11, pp. 43-45, 2005.

[17] W. Renhe and L. Bin, "Research on the phenomenon of multiple fracturing and fracture apertures of surrounding rock mass in deep roadway," Journal of China Coal Society, vol. 35, no. 6, pp. 887-890, 2010.

[18] B. N. Whittaker and E. L. Potts, "Appraisal of strata control practice," International Journal of Rock Mechanics and Mining Sciences \& Geomechanics Abstracts, vol. 11, no. 11, p. A225, 1974.

[19] B. H. D. Brady and E. T. Brown, "Energy changes accompanying underground mining," in Rock Mechanics for Underground Mining, pp. 240-259, Springer, Berlin, Germany, 1985.

[20] E. Hoek and M. S. Diederichs, "Empirical estimation of rock mass modulus," International Journal of Rock Mechanics and Mining Sciences, vol. 43, no. 2, pp. 203-215, 2006. 
[21] E. Hoek, T. G. Carter, and M. S. Diederichs, "Quantification of the geological strength index chart," in Proceedings of the 47th U.S. Rock Mechanics/Geomechanics Symposium, pp. 8, San Francisco, CA, USA, June 2013.

[22] H. Kose and Y. Cebi, "Investigation the stresses forming during production of thick coal seam," in Proceedings of the 6th Coal Congress of Turkey, Istanbul, Turkey, 1988.

[23] G. C. Zhang, F. L. He, H. G. Jia, and Y. H. Lai, "Analysis of gateroad stability in relation to yield pillar size: a case study," Rock Mechanics \& Rock Engineering, vol. 50, no. 5, pp. 1-16, 2017.

[24] J. Feng, S. Qian, and Z. Yonghui, "Research on distribution rule of shallow crustal geostress in China mainland," Chinese Journal of Rock Mechanics and Engineering, vol. 16, no. 10, pp. 2056-2062, 2007.

[25] D. Potyondy, "A flat-jointed bonded-particle material for hard rock," in Proceedings of the 46th US Rock Mechanics/ Geomechanics Symposium, Chicago, IL, USA, June 2012.

[26] S. Wu and X. Xu, "A study of three intrinsic problems of the classic discrete element method using flat-joint model," Rock Mechanics and Rock Engineering, vol. 49, no. 5, pp. 1813-1830, 2016.

[27] D. O. Potyondy and P. A. Cundall, “A bonded-particle model for rock," International Journal of Rock Mechanics and Mining Sciences, vol. 41, no. 8, pp. 1329-1364, 2004.

[28] G. Fu-Qjiang, K. Hongpu, and L. N. Jian, "Numerical simulation of zonal distrigation of surrounding rock," Journal of China Coal Society, vol. 35, no. 1, pp. 21-25, 2010. 